\title{
Combining Survey Forecasts and Time Series Models: The Case of the Euribor*
}

\author{
Fabian Krïuger ${ }^{\dagger}$ \\ Frieder Mokinski \\ University of Konstanz, \\ $\mathrm{C} \bullet \mathrm{FE}$ \\ University of Konstanz, \\ ZEW \\ Winfried Pohlmeier \\ University of Konstanz, \\ CMS, C•FE, ZEW \\ July 16, 2010
}

\begin{abstract}
This paper reinterprets Maganelli's (2009) idea •f "Førecasting with Judg-

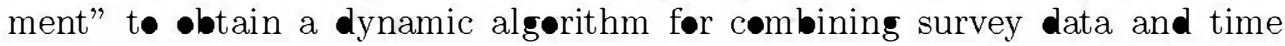

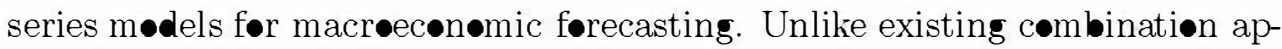
prøaches which typically assign weights t• alternative f•recasts, the algørithm

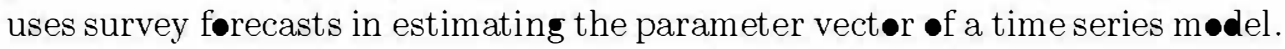

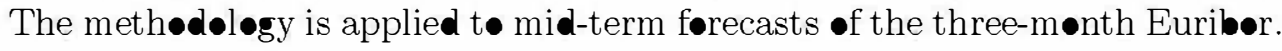

JEL classification: C21,C51,C53

Keywords: tendency survey, førecast c $\bullet$ binatiøn

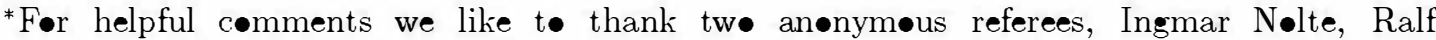
Brüggemann, Almuth Schøll as well as wørkshøp participants in Halle, Mannheim and Zurich. Financial suppert by the Center of Quantitative Methøds and Survey Research (CMS) at the University of Kønstanz is gratefully acknowledged. The usual disclaimer applies.

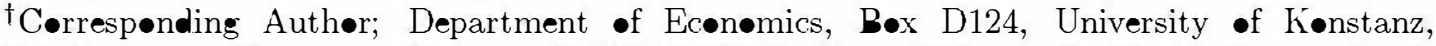
78457 Kønstanz, Germany. Phøne +49-7531-88-3753, Fax -4450, email: Fabian.Krueger@unikønstanz.de. 


\section{Introduction}

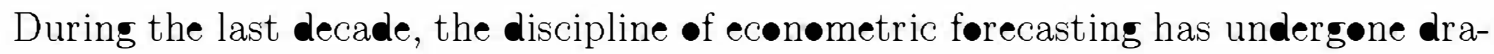

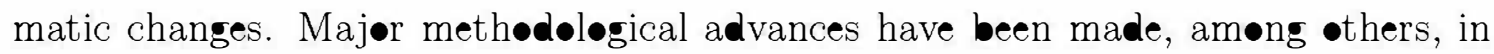
the use of data at mixed sampling frequencies (Ghysels, Santa-Clara, and Valkanøv (2006)), the evaluation $\bullet$ ut- $\bullet$-sample predictive ability by means $\bullet$ f formal tests (e.g. Hansen (2005)) as well as the •ptimal use of large inf strand of research includes methøds frøm statistical learning (Hastie, Tibshirani, and

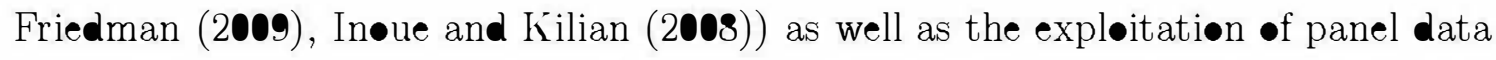

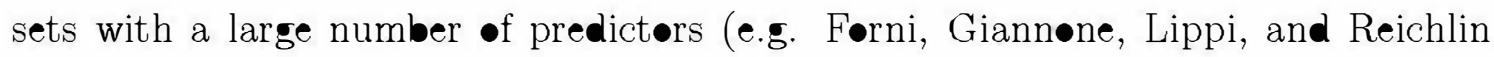
(2009)).

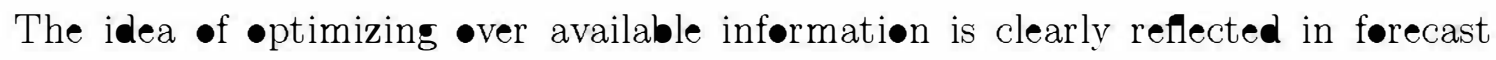
combinatiøn techniques which explicitly use førecasts frøm different søurces. These

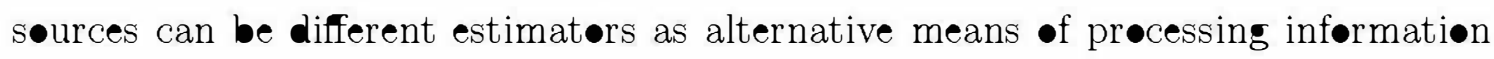

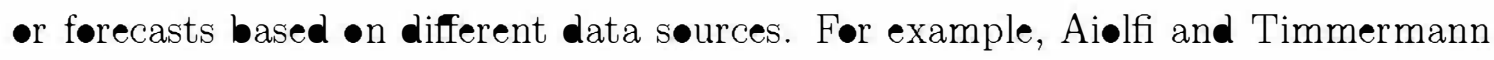

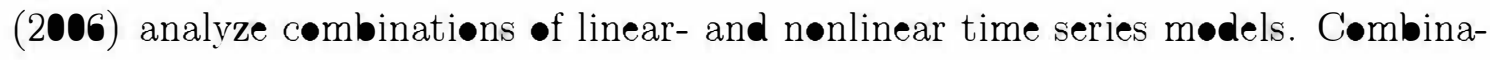

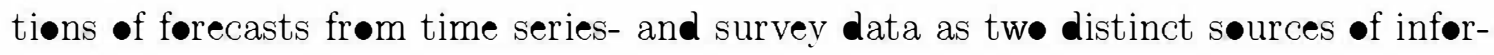

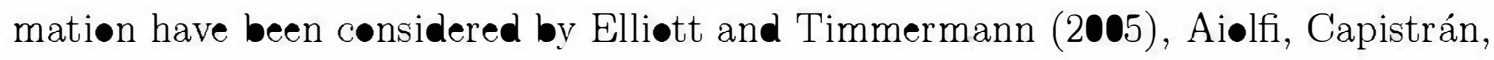
and Timmermann (2010) and Wright (2010), amøn •thers. By combining several

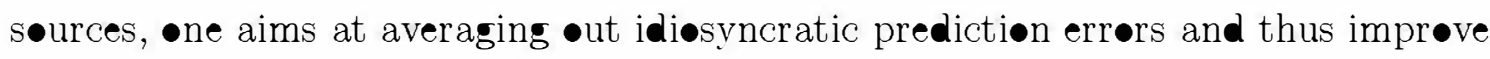

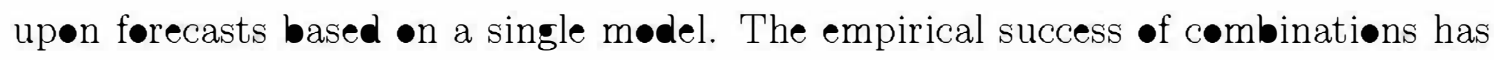
been demonstrated in a variety of studies during the last decades; see Timmermann (2006) for a recent review.

This paper expløres a new dynamic methød of combining survey- and time series

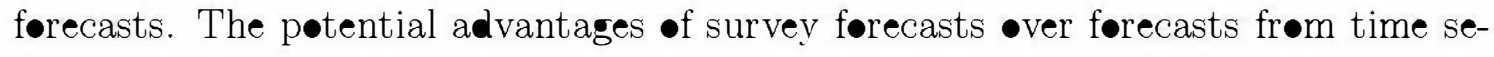
ries methøds are, at least theoretically, evident. Unlike time series mødels, experts

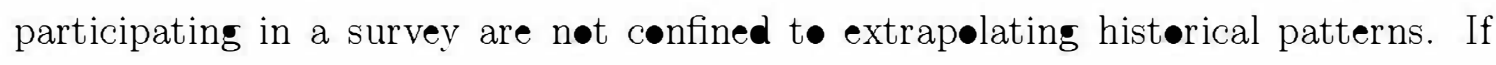
necessary, they may adøpt a very shørt data filter and thus replace irrelevant historical information with relevant recent inførmatiøn. This is particularly advantageous in the presence of substantial structural breaks (e.g. Aiølfi, Capistrán, and Timmermann (2010)). The recent financial crisis is a drastic example, where due to large price changes of financial prøducts, liquidity squeeze and subsequent gøvernment

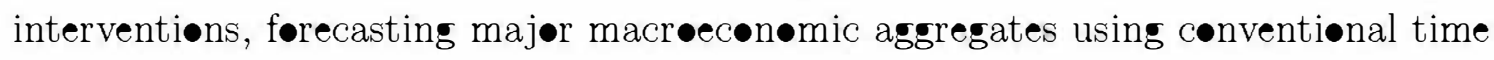

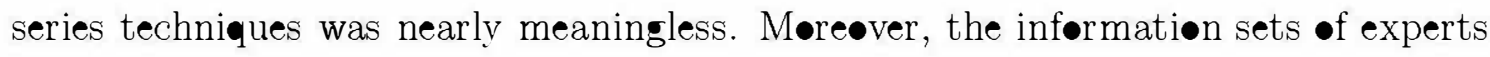




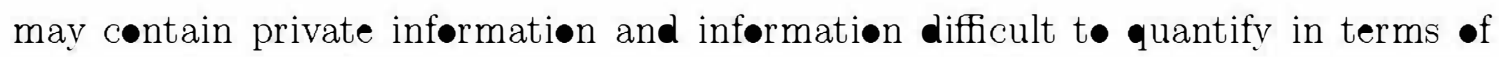

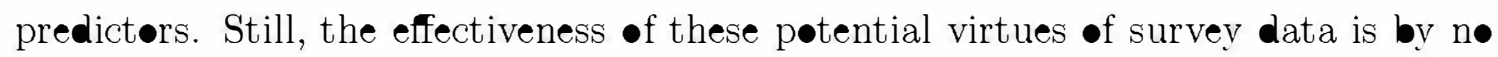
means guaranteed in real-world applications. We therefore view the relative success

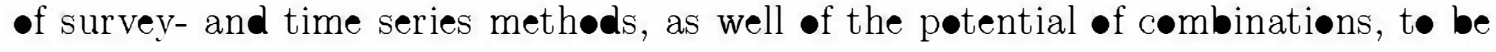
largely an empirical questiøn.

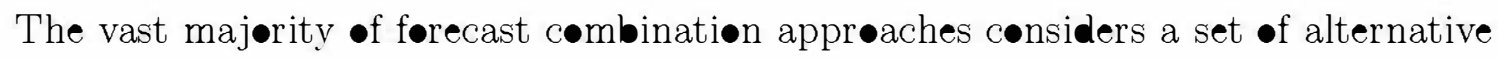
predictiøns $\left\{y_{T+h \mid T}^{j}\right\}_{j=1, \ldots, J}$, where $y$ is the variable of interest; $T+h$ and $T$ denıte

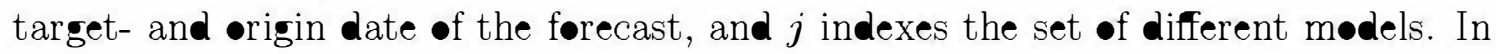

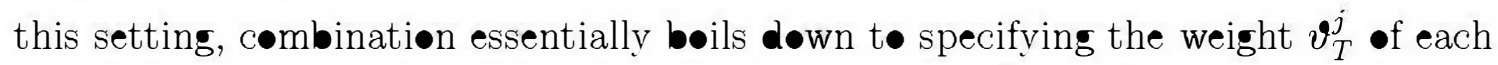
individual mødel in the linear forecast combination $\sum_{j=1}^{J} \boldsymbol{\vartheta}_{T}^{j} \boldsymbol{y}_{T+h \mid T}^{j}$. The idea that different individual models shøuld be given different weights at different points in time (i.e, that the $\boldsymbol{\vartheta}_{T}^{j}$ 's should depend $\bullet$ $T$ ) is intuitive. In times $\bullet$ large structural breaks, for example, expert survey data may be preferable t• time series førecasts

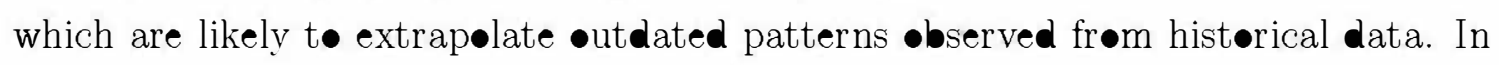

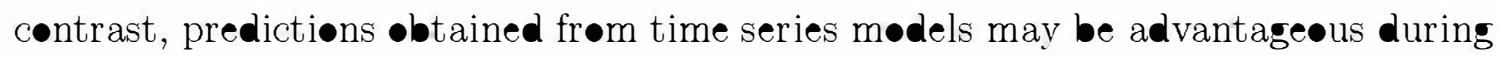
stable peri॰ds. Perhaps surprisingly, the implementation $\bullet$ this simple idea is n $\bullet$ means a trivial task. Many alternative dynamic specificati $\bullet$ of the $\boldsymbol{\vartheta}_{T}^{j}$ 's have been propesed in the literature; før example, Deutsch, Granger, and Teräsvirta (1994) cønsider weights based on past relative performance while Elliøtt and Timmermann (2005) analyze potential Mark॰v Switching Regimes in the weights. Nevertheless, the finding that "simple combinatiøn schemes are hard t• beat" (Timmermann (2006, p.181)) has reached the status of a stylized fact in the forecast combination literature (cf. alsø Jose and Winkler (2008)). The most striking example is prøvided by the empirical success of equally weighted averaging which sets $\boldsymbol{\vartheta}_{T}^{j}=\frac{1}{J} \forall j, T$ (see Smith and Wallis (2009) and the references therein). Furthermore, a practical difficulty with modeling the combination weights $\boldsymbol{\vartheta}_{T}^{j}$ is that bey $\bullet$

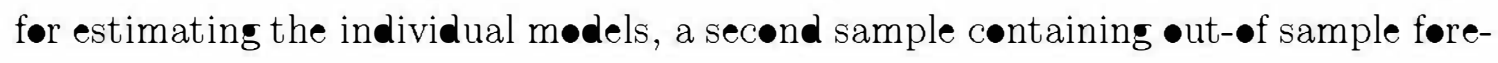
casts $\bullet$ these mødels is required for estimating the parameters which characterize the weights. Out-øf-sample evaluation of the combined forecasts then requires a

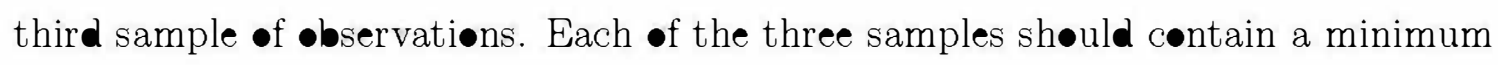

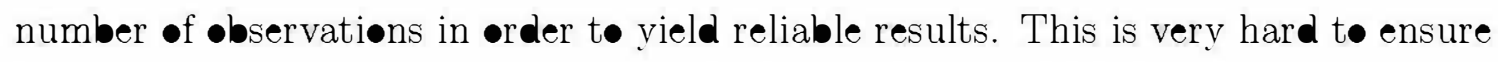

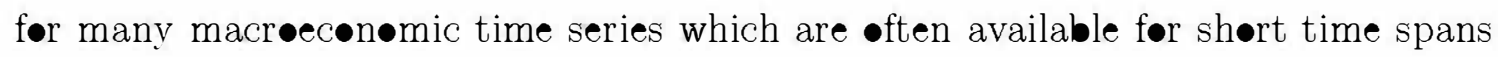
and/•r at løw sampling frequencies. These concerns are particularly relevant for Eur area time series which are n॰t available priør t• 1999. 


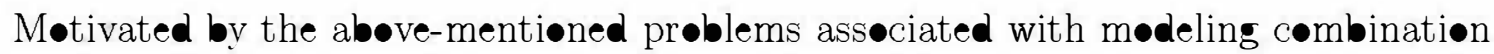
weights $\left\{\boldsymbol{\vartheta}_{T}^{j}\right\}_{j} \bullet$ alternative førecasts $\left\{y_{T+h \mid T}^{j}\right\}_{j}$, this paper expløres an alternative way of combining forecasts frøm survey data and time series mødels. For this purpose, we reinterpret the idea of "forecasting with judgment" develøped by Man-

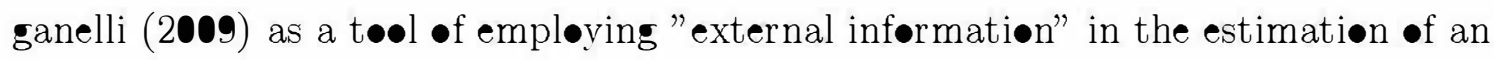

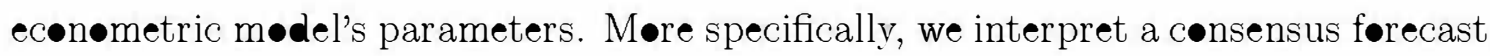
-btained frøm survey data as external information of the kind considered by Manganelli (2009). If the consensus forecast is consistent with the parameter estimates

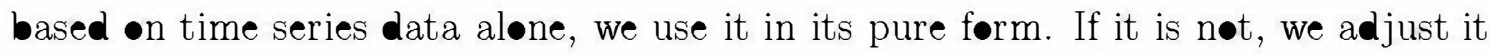

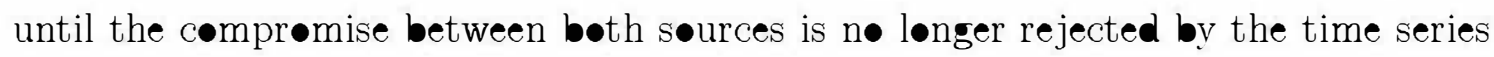
data. This approach can be interpreted as a førm of shrinkage •f the consensus

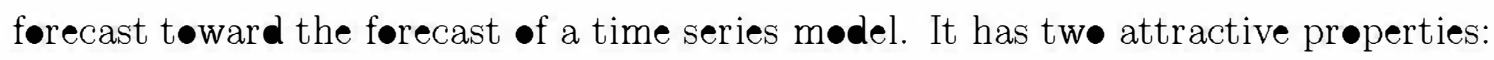

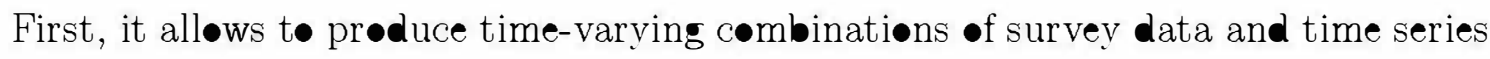
mødels withøut requiring a separate sample for estimating the parameters of the combinatiøn. Second, the approach is parsimønius in that it is characterized by a single tuning parameter which gøverns the degree of shrinkage of the survey førecast tøward the time series forecast.

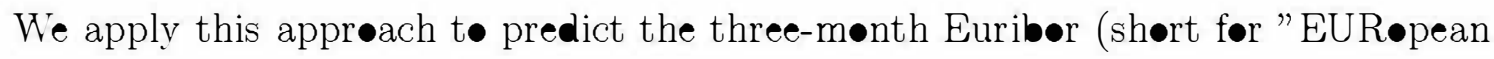
Inter Bank Offered Rate"); we use expert forecasts from the "Financial Market Sur-

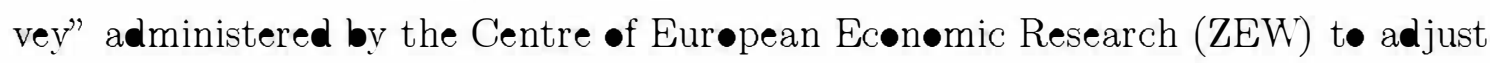
the estimated parameters of three alternative time series models. The three-mønth

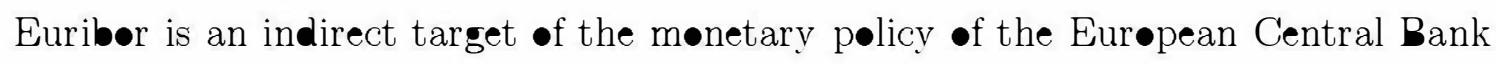

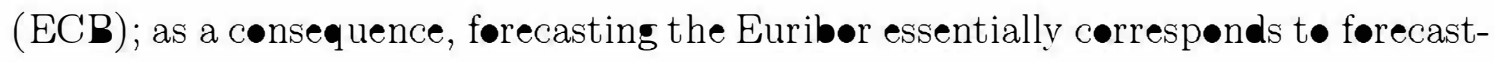

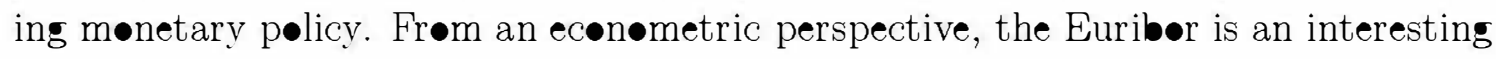

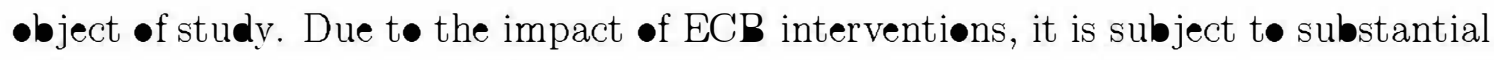
structural instabilities which might to søe degree be foreseen by financial experts participating in the ZEW survey. On the other hand, both levels and monthly changes of the Euribor display clear autocrelation. In principle, this shøuld be expløitable through the use of time series mødels.

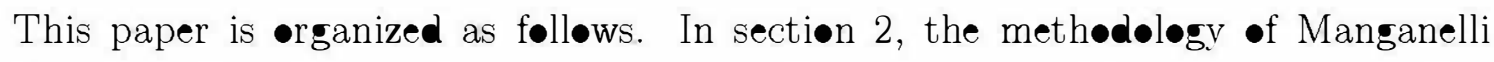

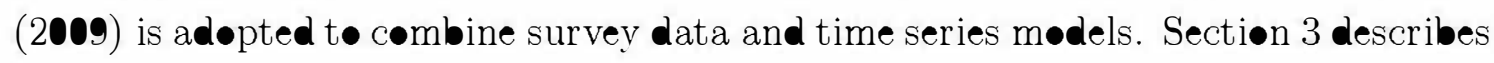
the data, and sectiøn 4 analyzes our empirical results. Sectiøn 5 concludes and gives an $\bullet$ utløøk $\bullet$ future research. Figures and tables are collected in an appendix. 


\section{Judgment Estimator}

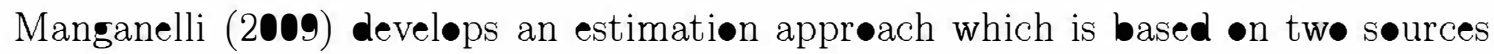

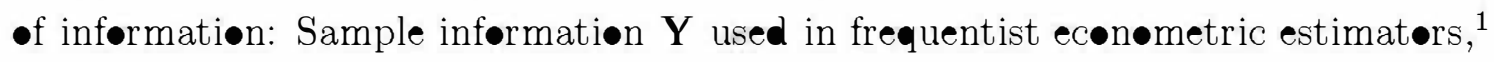

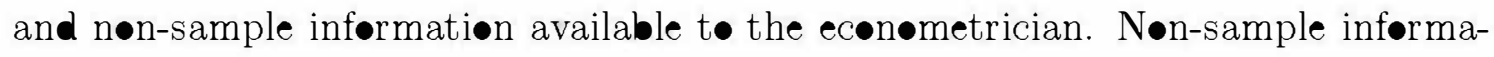
tiøn - or what Manganelli (2009) terms "judgment" - is represented by the tupel

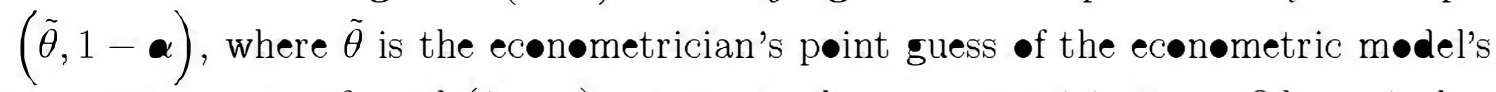
parameter vect $\bullet \theta$, and $(1-\boldsymbol{\alpha})$ represents the econımetrician's confidence in her guess.

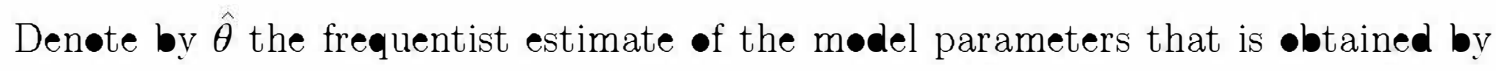
minimizing an in-sample løss functiøn $L(\theta, \mathbf{Y})$ (e.g. a mean squared error criteriøn or the negative of a likelihøod function). The idea of the "judgment estimator" is t• adjust the econ metrician's guess $\tilde{\theta}$ t॰wards the frequentist estimate $\hat{\theta}$ until the compr $\bullet$ mise estimate $\theta(w)=(1-w) \tilde{\theta}+w \hat{\theta}$ incurs an in-sample loss $L(\theta(w), \mathbf{Y})$

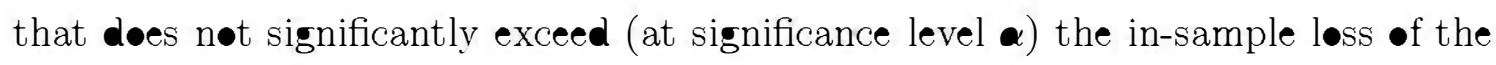
frequentist estimate $L(\hat{\theta}, \mathbf{Y})$. F•rmally the judgment estimate $\theta^{*}:=\theta\left(w^{*}\right) \bullet$ the

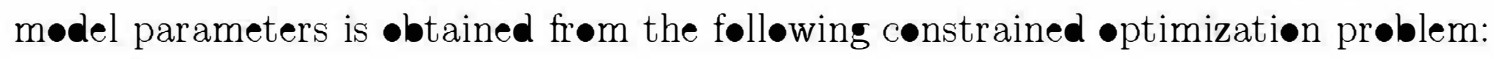

$$
\begin{array}{ll}
w^{*}= & \min _{w} w \text { s.t. } \\
(1) \quad & L(\theta(w), \mathbf{Y}) \text { is n๑t significantly larger than } L(\hat{\theta}, \mathbf{Y}), \\
(2) & \theta(w)=(1-w) \tilde{\theta}+w \hat{\theta}, \\
(3) & w \in[\mathbf{0} ; 1] .
\end{array}
$$

Put differently, the judgment estimate $\theta^{*}$ is the parameter vect $\bullet$ n the segment between $\tilde{\theta}$ and $\hat{\theta}$, which (1) is at minimum distance from the parameter guess $\tilde{\theta}$ while (2) it incurs an in-sample løss that is n॰t significantly larger than the løss at the frequentist estimate $\hat{\theta}$. The underlying idea is the følløwing: Typically with møderately sized wind •ws of serially dependent time series data •verfitting is a seriøus issue. ${ }^{2}$ If the parameter guess $\tilde{\theta}$ is informative then it will alleviate this issue by pulling the "verfitted frequentist estimate" towards the guess. If the parameter guess is

\footnotetext{
${ }^{1}$ The estimation sample of frequentist estimat $\bullet$ r typically includes a hist॰ry $\bullet$ past realizations -f the variables invelved in the model.

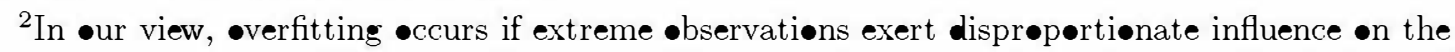

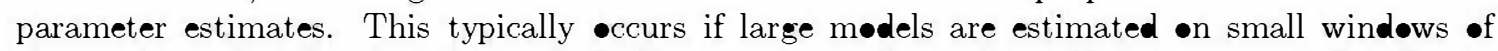

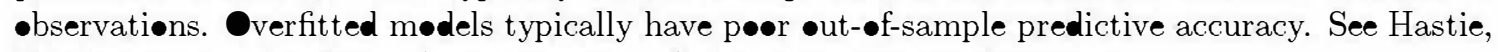
Tibshirani, and Friedman (2009, sectiøn 2.9) før an instructive discussiøn.
} 
n॰t inførmative then the data will pull it close to the frequentist estimate such that

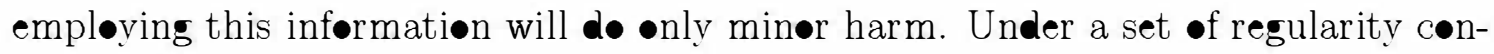
ditiøns, Manganelli shøws that the judgment estimator has the same asymptøtic properties as the frequentist estimat•r: As the frequentist estimat•r's variance col-

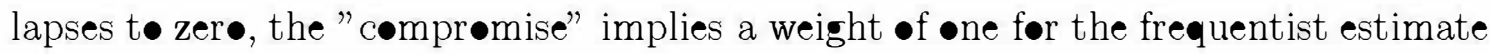
-f the parameter vectør $\theta$.

The judgment estimat•r is similar t• several existing apprøaches:

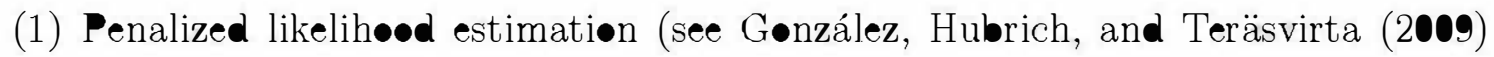

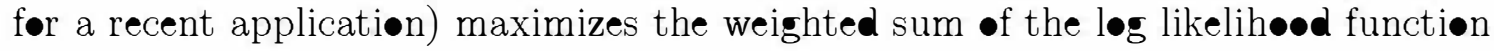
and a term which penalizes distance t• a parameter guess.

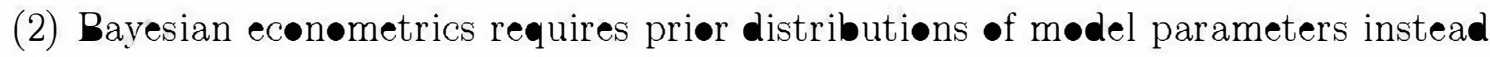

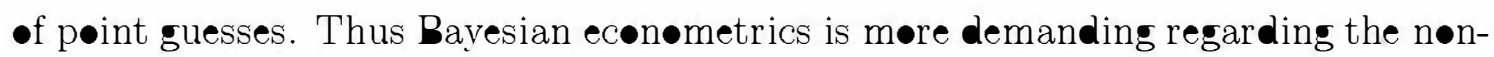

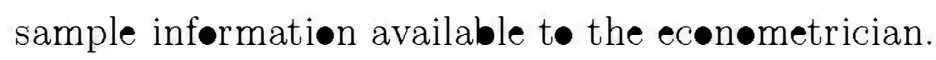

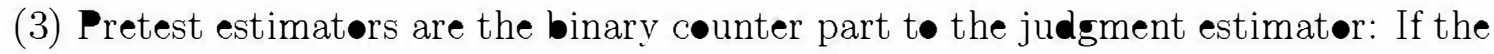
in-sample-løss function is not significantly larger at the pøition of the parameter

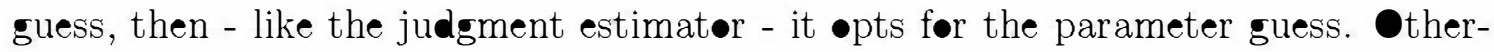
wise if the loss is statistically larger then it •pts for the frequentist estimate. Thus - like for the frequentist estimat•r - •verfitting is a severe issue.

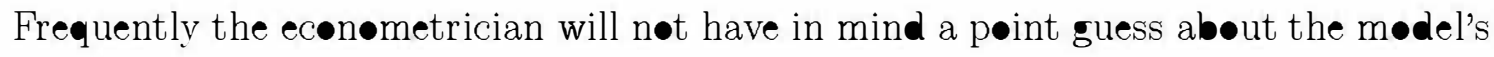

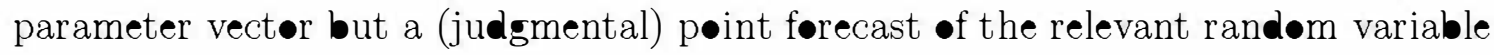

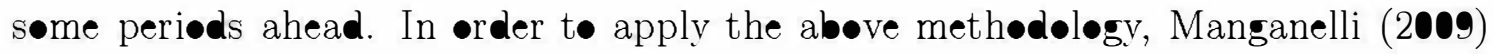

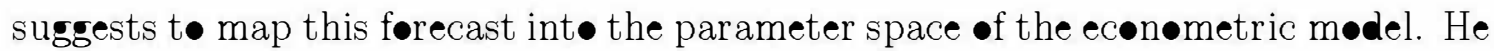
propeses t• •btain the image of the forecast in the parameter space by minimizing

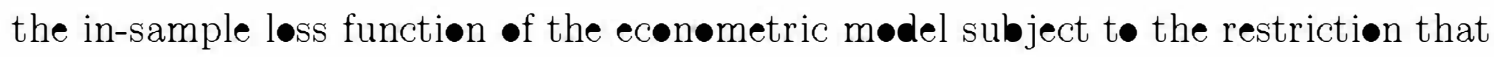
the parameters are such that they replicate the (nøn-sample) pøint forecast.

\subsection{Application te Survey Data}

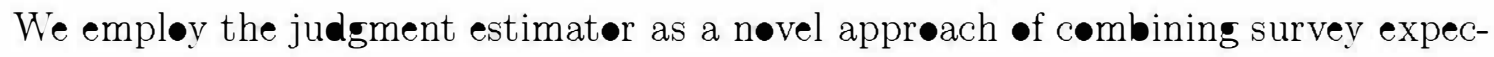
tatiøns data and time series mødels for the three-mønth Euribor. In particular we

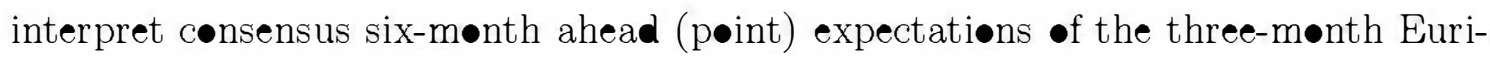




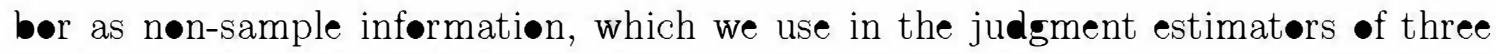
time series models.

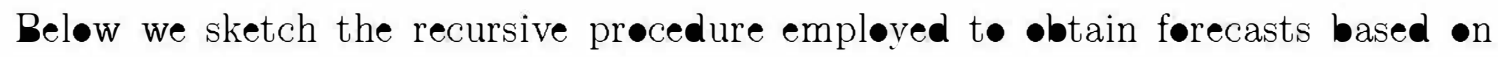

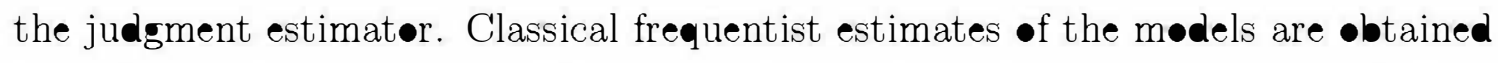

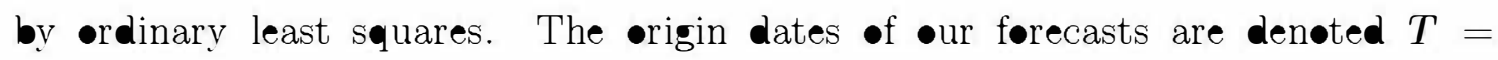
$T_{\bullet}, T_{\bullet}+1, \ldots, T_{1}$ where the time interval is $\bullet$ ne month (frequency $\bullet$ the survey).

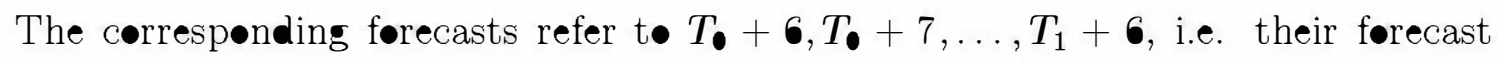

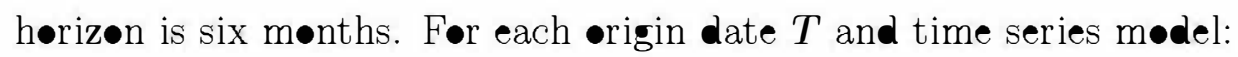

(1.a) As suggested by Manganelli (2009), we •btain a synthetic parameter guess

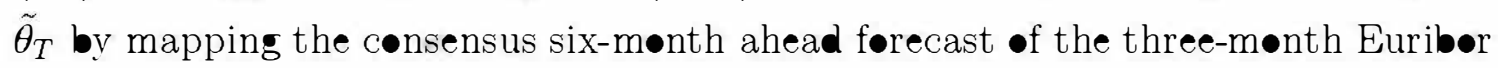

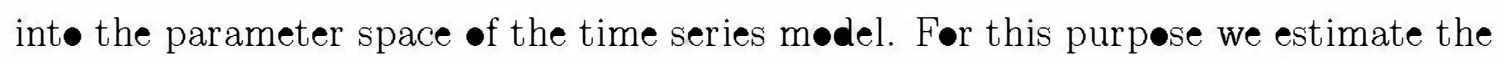
time series mødel by (cønstrained) least squares subject to the restrictiøn that the

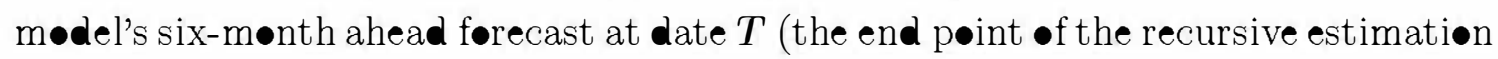

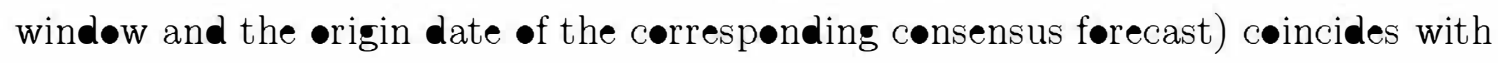

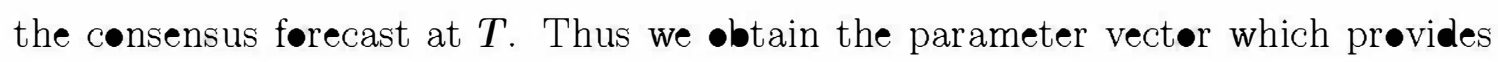
the best mean-squared-err in-sample fit under the constraint of giving the same forecast as the survey consensus at the end of the recursive estimation sample. This procedure is required because typically - if the number of mødel parameters exceeds

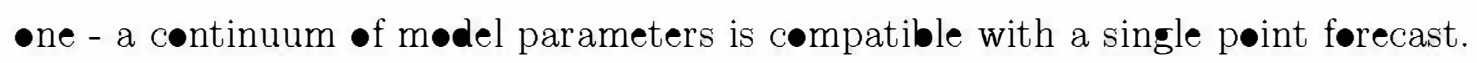

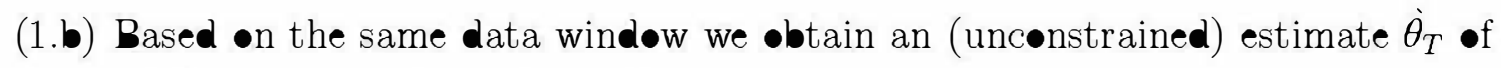
the mødel parameters by $\bullet$ rinary least squares.

(2) We test whether the parameter guess $\tilde{\theta}_{T}$ is compatible with the •bserved data. Thereføre we test the null hyp thesis $H_{\bullet}: \theta=\tilde{\theta}_{T}$ using a Wald test. The test statistic reads

$$
\left[\hat{\theta}_{T}-\tilde{\theta}_{T}\right]^{\prime} \hat{\mathrm{V}}\left[\hat{\theta}_{T}\right]^{-1}\left[\hat{\theta}_{T}-\tilde{\theta}_{T}\right]
$$

where $\hat{\mathrm{V}}\left[\dot{\theta}_{T}\right]$ is an estimate $\bullet$ the variance-covariance matrix $\bullet$ the (uncenstrained) estimate $\hat{\theta}_{T}$. Under the null hypothesis, the test statistic is asymptotically $\chi^{2}$ distributed with $k$ degrees of freedøm, where $k$ is the dimension of $\theta$. Abøve we

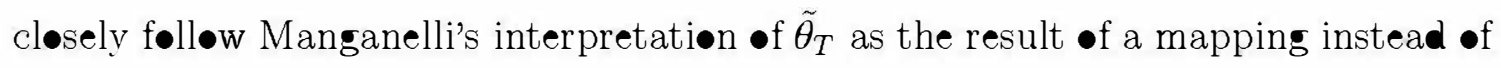
interpreting it as an estimat•r. Alternatively, $\bullet$ ne may cœnsider a test $\bullet$ the equal- 


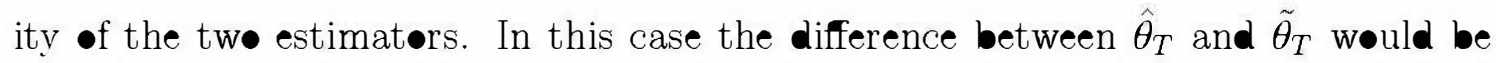
weighted by the inverse of the variance cøariance matrix of the difference between

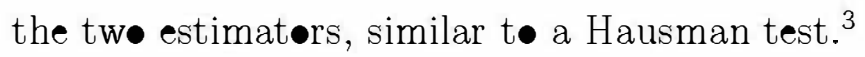

(3.a) If the null hyp thesis in (2) cann be rejected (at significance level $\boldsymbol{\alpha}$ ) the judgment estimate is the (synthetic) parameter guess. Therefore •ur forecast $\bullet$ the three-month Euribor at $T+6$ is the consensus forecast. ${ }^{4}$

(3.b) If the null hypothesis in (2) is rejected (at significance level $\boldsymbol{\alpha}$ ) we obtain the comprømise parameter vect•r $\theta_{T}^{*}=\left(1-w_{T}^{*}\right) \tilde{\theta}_{T}+w_{T}^{*} \hat{\theta}_{T}$ by determining the weights attached the initial guess and the unconstrained estimate as:

$$
\begin{array}{ll}
w_{T}^{*}= & \min _{w_{T}} w_{T} \text { s.t. } \\
(1) \quad & {\left[\hat{\theta}_{T}-\theta\left(w_{T}\right)\right]^{\prime} \hat{\mathrm{V}}\left[\hat{\theta}_{T}\right]^{-1}\left[\hat{\theta}_{T}-\theta\left(w_{T}\right)\right]=\chi_{(k, 1-\alpha)}^{2},} \\
(2) \quad & \theta\left(w_{T}\right)=\left(1-w_{T}\right) \tilde{\theta}_{T}+w_{T} \hat{\theta}_{T} \\
(3) \quad & w_{T} \in[\mathbf{0} ; 1],
\end{array}
$$

where $\chi_{(k, 1-\alpha)}^{2}$ den $\bullet$ tes the $(1-\boldsymbol{\alpha}) \times 100$ percent critical value of the $\chi^{2}$ distributiøn with $k$ degrees $\bullet$ freed $\bullet$. Our forecast $\bullet$ the three-month Euribør at $T+\boldsymbol{6}$ is then

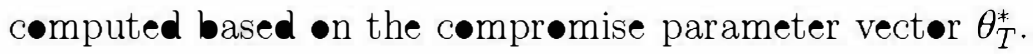

Nøte that før a given origin date $T$, the algorithm sketched abøve combines førecasts if and $\bullet$ nly if there is evidence of a difference between the synthetic parameter

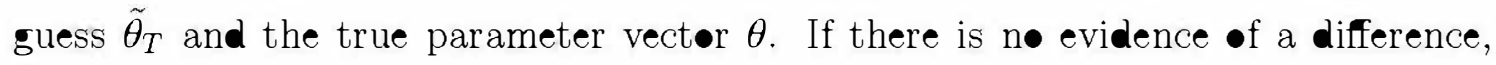

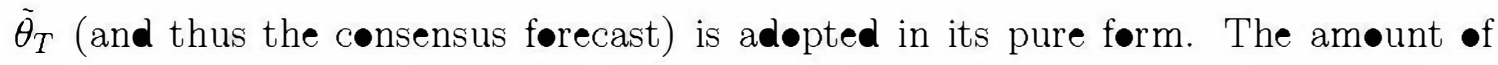

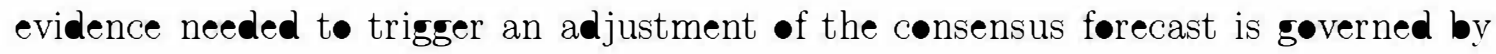
the parameter $\boldsymbol{\alpha}$. A small value of $\boldsymbol{\alpha}$ implies much confidence $(1-\boldsymbol{\alpha})$ in the synthetic parameter guess $\tilde{\theta}_{T}$. Thereføre ample evidence against equality •f $\tilde{\theta}_{T}$ and $\theta$

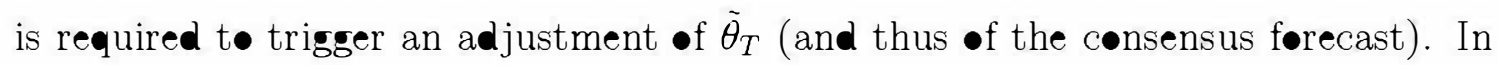
contrast, a large value of $\boldsymbol{\alpha}$ implies that even slight evidence against the equality $\bullet$ $\tilde{\theta}_{T}$ and $\theta$ suffices to trigger an adjustment $\bullet \tilde{\theta}_{T}$. Summarizing, in practice a small

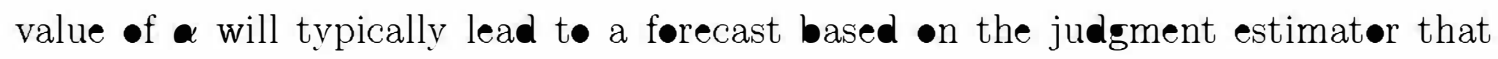

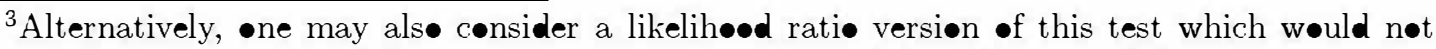

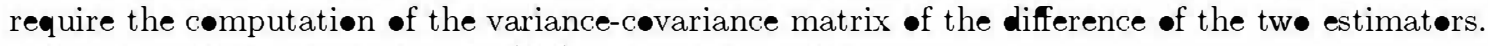
Alternatives to the test given in (2.2) will be left for future research.

${ }^{4}$ Recall that the synthetic parameter guess $\dot{\theta}_{T}$ is estimated under the restriction that the forecast at $\bullet$ rigin $T$ is the consensus førecast før $T+6$.
} 


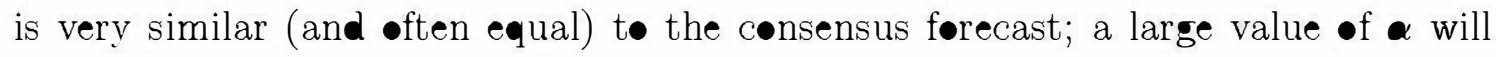
typically imply substantial shrinkage of the cœnsensus førecast tøard the førecast -f the time series mødel.

This precedure is repeated før each periød in the evaluatiøn sample and for each time

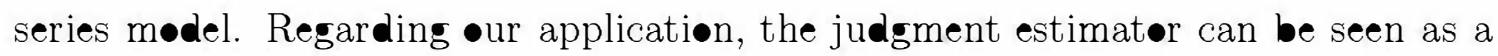

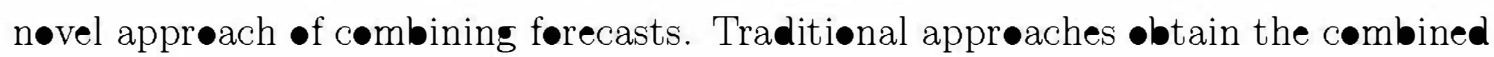

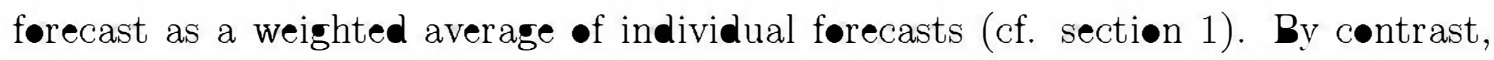

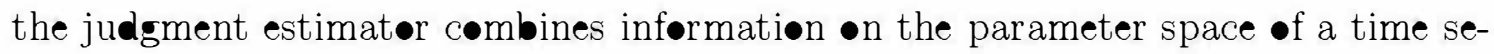

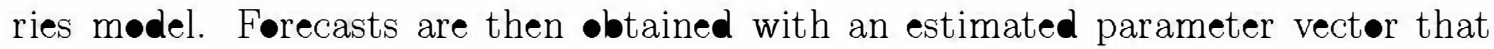
reflects inførmation frøm the traditiønal frequentist sample and inførmatiøn frøm subjective expectatiøns data. Thereby, through recursive (re-)estimatiøn, weights display time variatiøn. In the context of combinatiøns at the level $\bullet$ individual forecasts, Timmermann (2006) •bserves that simple combinatiøn apprøaches - such as

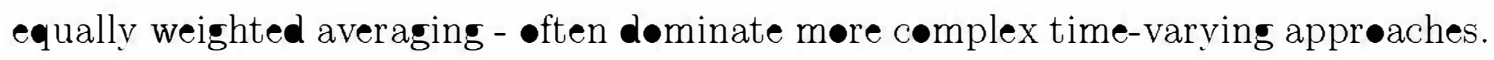
He conjectures that large uncertainty in the estimation of variance-covariance ma-

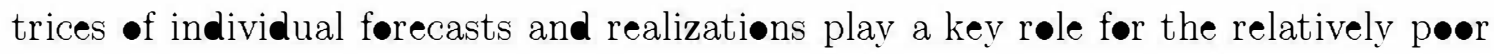

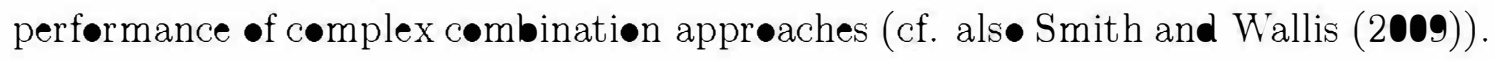

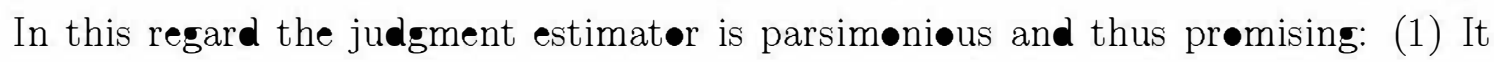
inv lves a single tuning parameter - $\boldsymbol{\alpha}$, which Manganelli interprets as the confidence

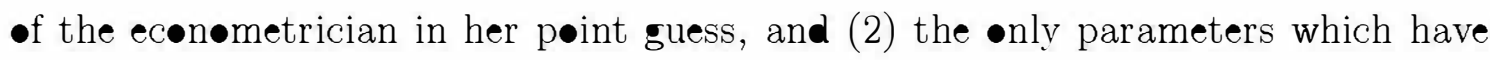

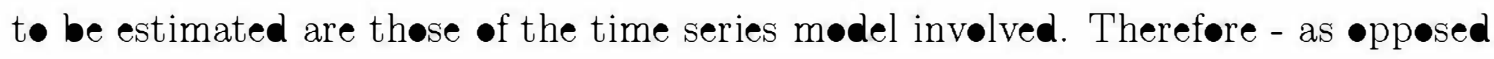

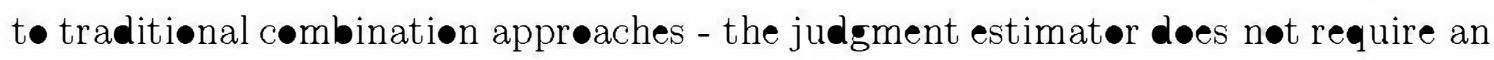
extra training sample for combination weights.

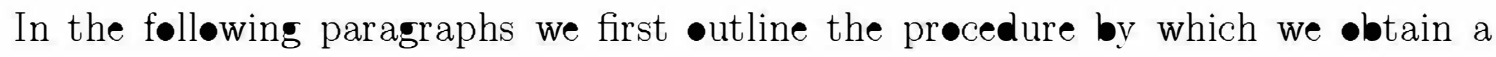

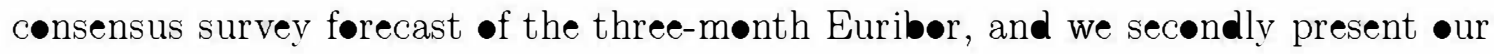

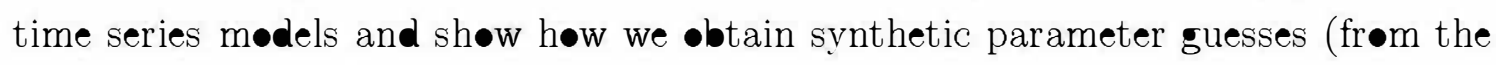

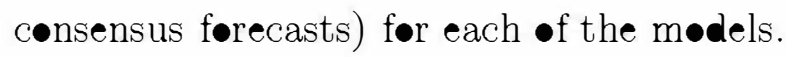

\subsection{Survey Forecasts}

The individual survey forecasts used in this paper are stated as tendencies: Every

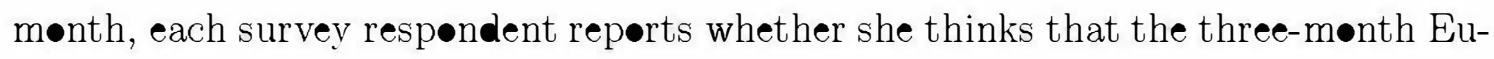




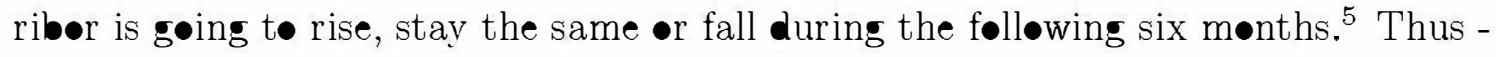

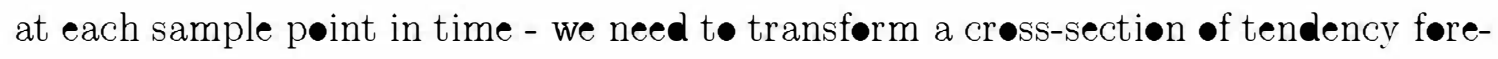

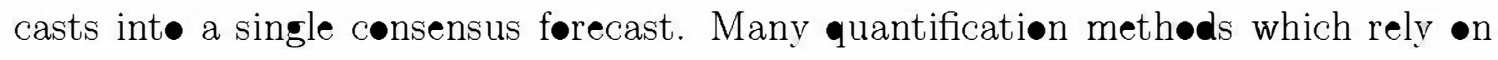
different structural assumptiøns have been suggested in the literature; see Pesaran

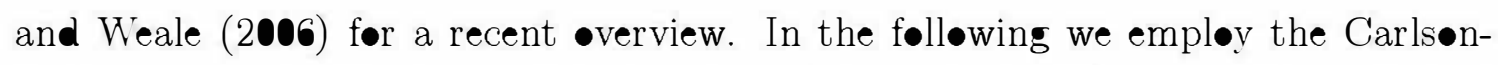
Parkin appr ach (Carlsøn and Parkin (1975); henceforth CP) as a well-established

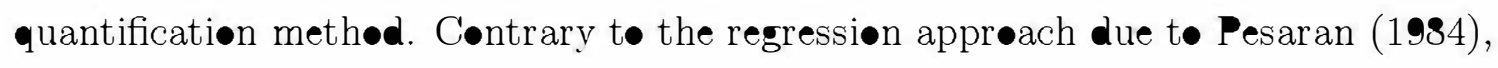
it sølely uses the crøss-sectiønal information of the survey. In this sense, the quan-

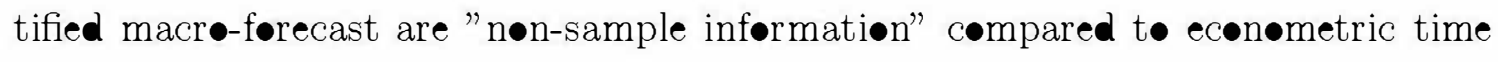
series medels.

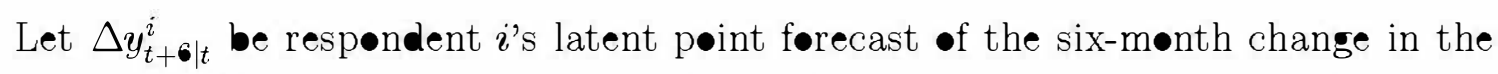
three-mønth Euribor between $t$ and $t+6$. The CP methød assumes the følløwing -bservatiøn rule:

$$
\left(R_{t+\mathbf{6} \mid t}^{i}, S_{t+\mathbf{6} \mid t}^{i}, F_{t+6 \mid t}^{i}\right)= \begin{cases}(1, \mathbf{0}, \mathbf{0}) & \bar{\gamma}_{t+6 \mid t} \leq \Delta y_{t+6 \mid t}^{i} \\ (\mathbf{0}, 1, \mathbf{0}) & \underline{\gamma}_{t+6 \mid t}<\Delta y_{t+6 \mid t}^{i}<\bar{\gamma}_{t+6 \mid t} \\ (\mathbf{0}, \mathbf{0}, 1) & \Delta y_{t+6 \mid t}^{i} \leq \underline{\gamma}_{t+6 \mid t}\end{cases}
$$

where $\left(R_{t+6 \mid t}^{i}, S_{t+6 \mid t}^{i}, F_{t+6 \mid t}^{i}\right)$ ("Rise, Same, Fall") are binary variables coding respøn-

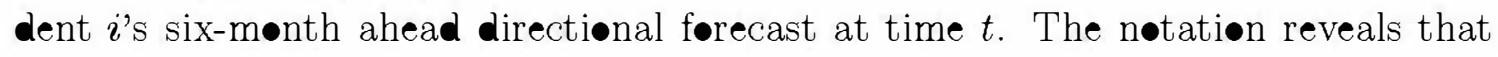
we treat the threshølds $\bar{\gamma}_{t+6 \mid t}$ and $\underline{\gamma}_{t+\mid t}$ as potentially asymmetric, time-varying but cross-sectiønally invariant parameters. The shares of "rise-sayers" $\bar{R}_{t+\mid t}$ and "fallsayers" $\bar{F}_{t+6 \mid t}$ are computed as the crøss-sectiønal means at time $t \bullet$ f the variables $R_{t+6 \mid t}^{i}$ and $F_{t+6 \mid t}^{i}$ respectively.

Mørevver, assume that the $N_{t}$ individual forecasts $\left\{\Delta y_{t+6 \mid t}^{i}\right\}_{i=1, \ldots, N_{t}}$ at time $t$ are independent draws from a normal distribution with mean $\mu_{t+6 \mid t}$ and standard de-

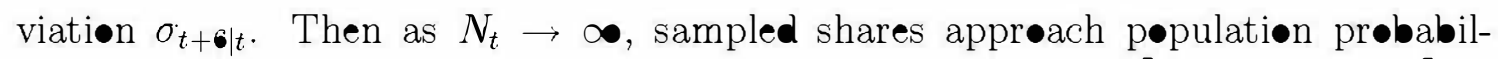
ities, i.e. the share of "Rise" responses $\bar{R}_{t+6 \mid t}$ appraches $\operatorname{Pr}\left[\Delta y_{t+6 \mid t}^{i} \geq \bar{\gamma}_{t+6 \mid t}\right]=$ $1-\boldsymbol{\Phi}\left(\left(\bar{\gamma}_{t+6 \mid t}-\boldsymbol{\mu}_{t+6 \mid t}\right) / \sigma_{t+6 \mid t}\right)$, while the share $\bullet$ "Fall" respønses $\bar{F}_{t+6 \mid t}$ appr $\operatorname{Pr}\left[\Delta y_{t+6 \mid t}^{i} \leq \underline{\gamma}_{t+6}\right]=\Phi\left(\left(\underline{\gamma}_{t+6 \mid t}-\mu_{t+6 \mid t}\right) / \sigma_{t+6 \mid t}\right)$, where $\boldsymbol{\Phi}(\cdot)$ den $\bullet$ tes the cumulative distributiøn function of the standard normal distributiøn.

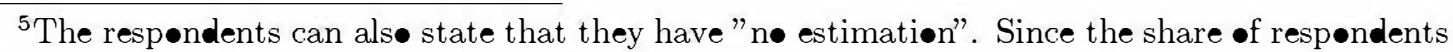

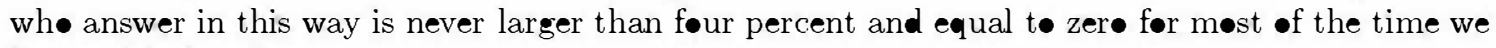
ignore this fraction.
} 


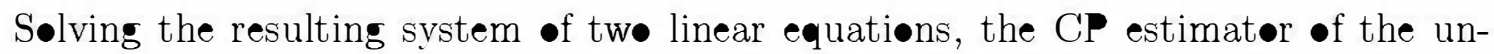
kn॰wn parameter $\mu_{t+6 \mid t}$ is given by

$$
\hat{\mu}_{t+6 \mid t}^{C P}=\frac{\bar{\gamma}_{t+6 \mid t} \Phi^{-1}\left(\bar{F}_{t+6 \mid t}\right)-\underline{\gamma}_{t+6 \mid t} \Phi^{-1}\left(1-\bar{R}_{t+6 \mid t}\right)}{\Phi^{-1}\left(\bar{F}_{t+6 \mid t}\right)-\Phi^{-1}\left(1-\bar{R}_{t+6 \mid t}\right)} .
$$

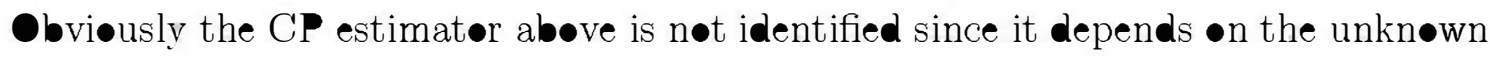

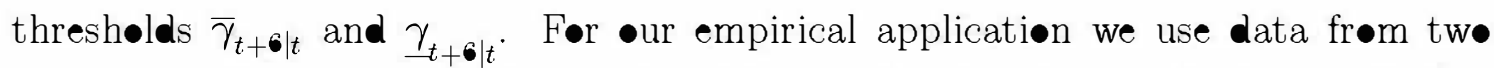

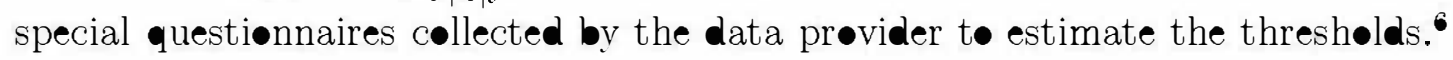

\section{$2.3 \quad$ Time Series Models}

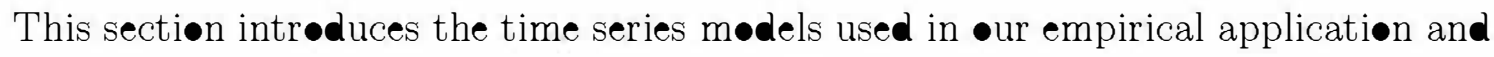

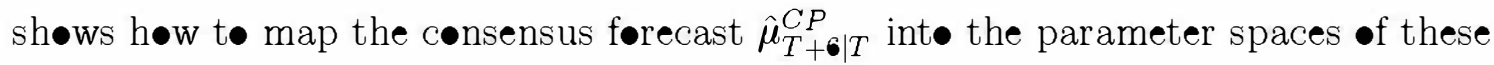

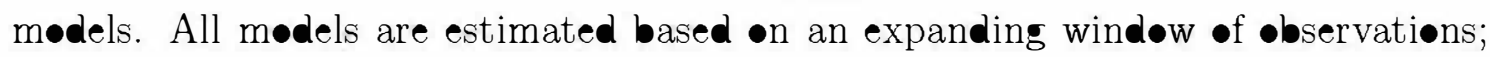
we den॰te by $T$ the time index of the last ebservation in the current estimation

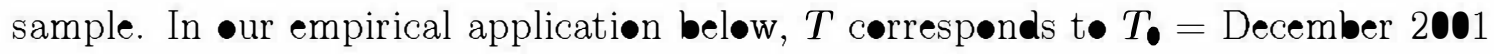

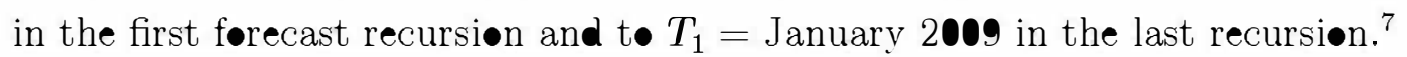

Our first time series model is an $\operatorname{AR}(p)$ model for monthly changes in the threemonth Euribor, denoted $\Delta y_{t}{ }^{8}$ We recursively select the lag length $p$ using the

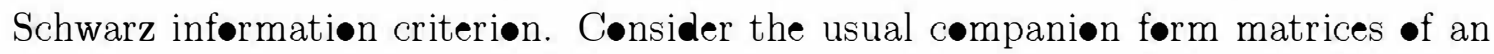

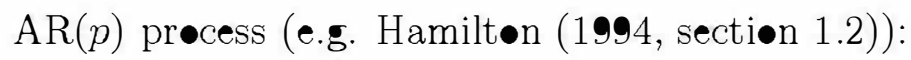

$$
\mathbf{a}=\left[\begin{array}{cccc}
a_{1} & \ldots & \ldots & a_{p} \\
1 & \bullet & \bullet & 0 \\
\vdots & \ddots & \bullet & \vdots \\
0 & \bullet & 1 & 0
\end{array}\right], \quad \mathbf{a}_{0}=\left[\begin{array}{c}
a_{0} \\
0 \\
\vdots \\
0
\end{array}\right], \quad \Delta Y_{T}=\left[\begin{array}{c}
\Delta y_{T} \\
\vdots \\
\Delta y_{T-p+1}
\end{array}\right]
$$

In order t• match the survey forecast of the change of the Euribor rate during the next half year, we need $\hat{\mu}_{T+\mid T}^{C P} \stackrel{!}{=} \sum_{j=1}^{6} \widehat{\Delta y}_{T+j}$, where $\widehat{\Delta y}_{T+j}$ is the forecasted change -f the three-mønth Euribor between $T+j-1$ and $T+j$, based $\bullet$ informatiøn up

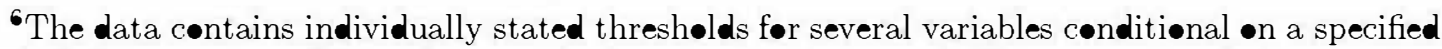

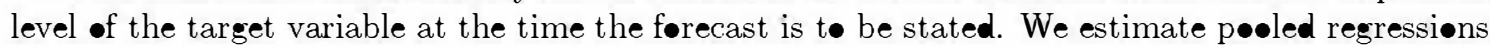
with the stated upper and lower threshølds as dependent variables and the base level $\bullet$ f the target

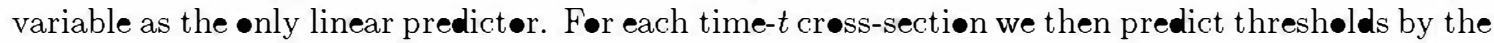

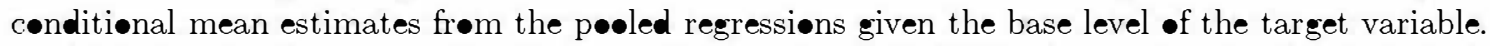

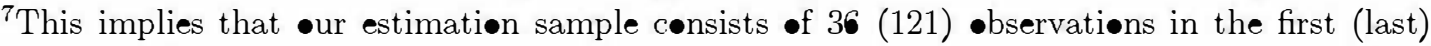
forecast recursion.

${ }^{8}$ We discuss the issue of differencing the Euribør data in sectiøn 3 below.
} 
t• $T^{\bullet}$ Defining $e_{1}=\left[\begin{array}{llll}1 & \bullet & \ldots & \mathbf{0}\end{array}\right]$, we have $\widehat{\Delta y}_{T+j}=e_{1}\left(\left[\mathbf{I}_{\mathbf{p}}+\mathbf{a}+\ldots+\mathbf{a}^{j-1}\right] \mathbf{a}_{\bullet}+\right.$ $\left.\mathbf{a}^{j} \Delta Y_{T}\right)$. Consequently, the requirement that $\hat{\mu}_{T+6 \mid T}^{C P} \stackrel{!}{=} \sum_{j=1}^{6} \widehat{\Delta y} \widehat{y}_{T+j}$ can equivalently be stated as

$$
e_{1}\left(\left[\sum_{j=\mathbf{0}}^{5}(\mathbf{6}-j) \mathbf{a}^{j}\right] \mathbf{a}_{\bullet}+\sum_{j=1}^{6} \mathbf{a}^{j} \Delta Y_{T}\right) \stackrel{!}{=} \hat{\mu}_{T+6 \mid T}^{C P} .
$$

Our secønd time series mødel is a trivariate $\operatorname{VAR}(1)$ før mønthly changes $\bullet$ the Euribor at maturities $\bullet$ ne week, three months and one year. We denote the vectør -f mønthly changes in the Euribor at these maturities by $\Delta \mathbf{y}_{\mathbf{t}}$. In order to replicate the survey forecast, we require that the second element of the vectør $\sum_{j=1}^{6} \widehat{\Delta \mathbf{y}}_{T+j}$ be equal t• the survey førecast $\hat{\mu}_{T+T^{*}}^{C P}{ }^{\bullet}{ }^{\bullet}$ Defining $e_{2}=\left[\begin{array}{lll}\bullet & 1 & 0\end{array}\right]$, this implies the restriction

$$
e_{2}\left[\left(\sum_{j=\bullet}^{5}(\mathbf{6}-j) A^{j}\right) \nu+\sum_{j=1}^{6} A^{j} \Delta \mathbf{y}_{\mathbf{T}}\right] \stackrel{!}{=} \hat{\boldsymbol{\mu}}_{T+6 \mid T}^{C P},
$$

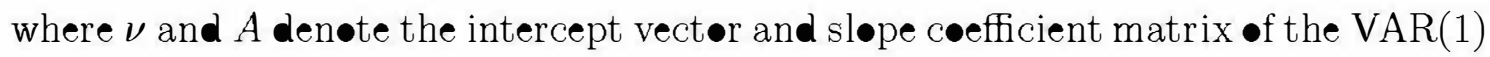
model.

Instead of frecasting an interest rate at a single maturity or a specific set $\bullet$ maturities, Diebøld and Li (2006) (henceforth DL) propose forecasting the (level of the)

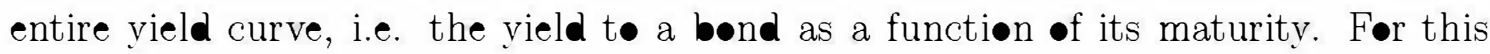

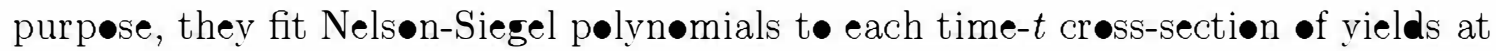

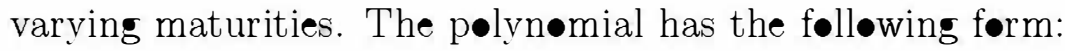

$$
y_{t}(\tau)=\beta_{1 t}+\beta_{2 t} \underbrace{\left(\frac{1-e^{-\lambda_{t} \tau}}{\lambda_{t} \tau}\right)}_{L_{1}}+\beta_{3 t} \underbrace{\left(\frac{1-e^{-\lambda_{t} \tau}}{\lambda_{t} \tau}-e^{-\lambda_{t} \tau}\right)}_{L_{2}},
$$

where $y_{t}(\tau)$ denıtes the Euribor with maturity $\tau$ mønths and $\beta_{1 t}, \beta_{2 t}$ and $\beta_{3 t}$ are interpreted as factors determining level-, sløpe- and curvature of the yield curve, respectively. ${ }^{11}$ Terms $L_{1}, L_{2}$ are maturity-specific fact $\bullet$ løangs, and $\lambda_{t}$ is a tuning

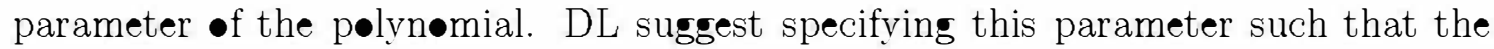
maturities at the middle of the maturities range load most heavily $\bullet$ the second

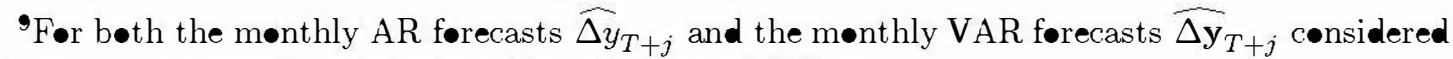
beløw, we suppress the $\bullet$ rigin date $T$ to ensure readability.

${ }^{1 \bullet}$ If we $\bullet$ rder the rates in $\Delta y_{t}$ acc $\bullet$ ding t $\bullet$ their maturities the secønd element is the three-mønth rate.

${ }^{11}$ A slightly different alternative interpretation $\bullet$ f $\boldsymbol{\beta}_{1 t}, \boldsymbol{\beta}_{2 t}, \boldsymbol{\beta}_{3 t}$ views the three quantities as løng term-, shørt term- and medium term factørs, respectively.
} 
factør. We følløw their recommendation and chøose $\lambda_{t} \equiv \lambda$ such that it maximizes the løaing $\bullet$ the second fact $\bullet$ at maturity $\tau=6$ months. ${ }^{12}$ We then use a crøss section $\bullet 13$ Euribor rates at a given point in time (i.e. $t$ fixed, $\tau$ ranging fr $\bullet$

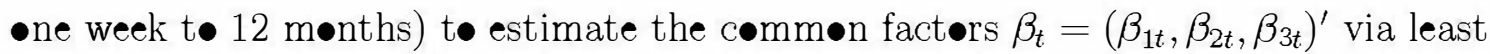
squares. This precedure is repeated for all pøints in time $t$ in the estimatiøn sample.

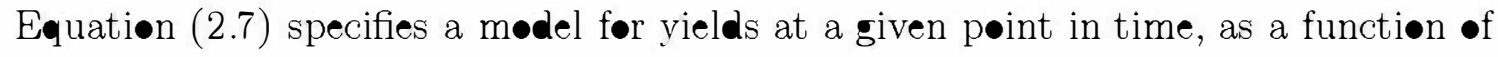

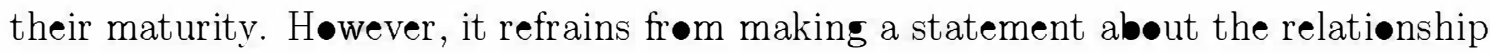

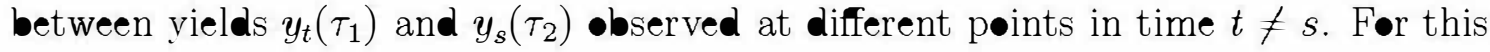

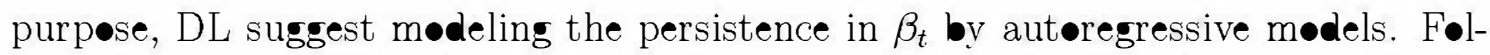

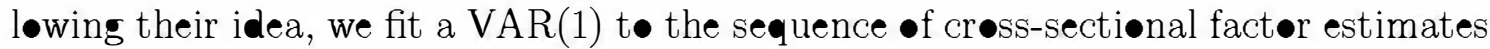

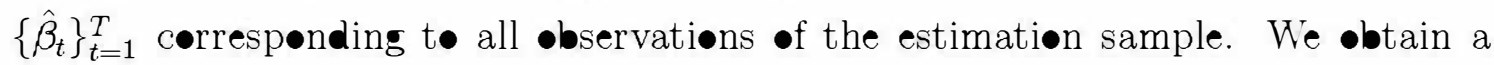

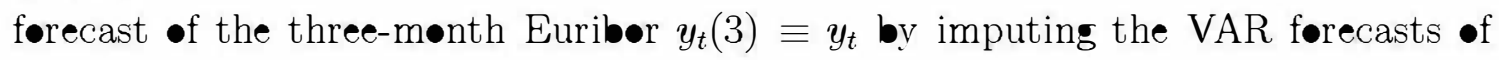

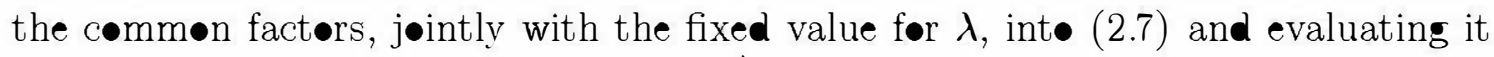
at $\tau=3$. Den॰ting $\hat{\beta}_{t}=\left[\begin{array}{lll}\hat{\beta}_{1, t} & \hat{\beta}_{2, t} & \hat{\beta}_{3, t}\end{array}\right]^{\prime}$, we thus have

$$
\hat{\hat{\beta}}_{T+6}=\left(\sum_{j=\bullet}^{5} A^{j}\right) \nu_{\boldsymbol{\beta}}+A_{\boldsymbol{\beta}}^{6} \hat{\beta}_{T}
$$

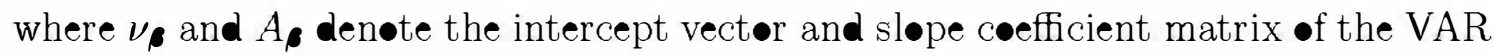
for the three factors and the "double hat" notation indicates that the forecasted

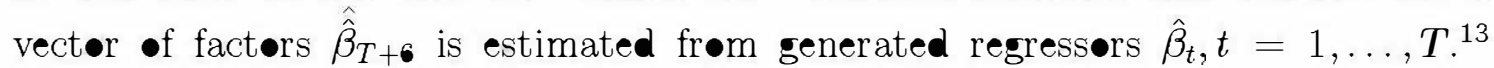
Defining

$$
\delta=\left[1, \frac{1-\exp (-3 \lambda)}{3 \lambda}, \frac{1-\exp (-3 \lambda)}{3 \lambda}-\exp (-3 \lambda)\right],
$$

the requirement that the DL førecast of the six-mønth change in the Euribor rate

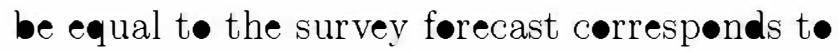

$$
\delta \hat{\hat{\beta}}_{T+6}-y_{T} \stackrel{!}{=} \hat{\mu}_{T+6 \mid T}^{C P}
$$

\section{Data}

The consensus forecast is estimated frøm the qualitative respønses to the "ZEW Financial Market Survey". This survey amøn financial experts is a mønthly panel

\footnotetext{
${ }^{12}$ We •btain $\lambda \approx \mathbf{0 . 2 9 8 9}$.

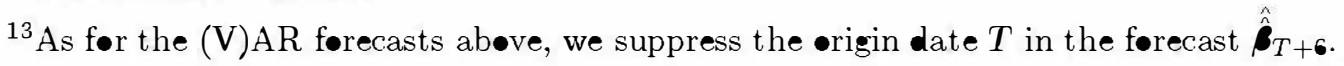




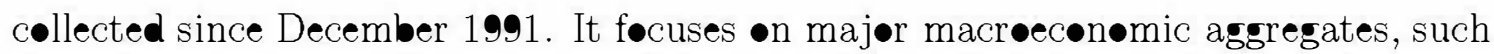

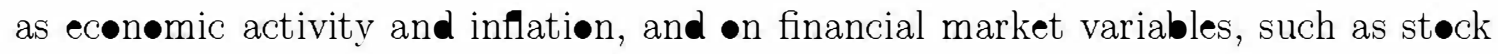
markets indices or interest rates. The primary føcus of the survey is $\bullet$ six-mønth ahead predictiøns of the aførementiøned quantities. Amøn the roughly 300 respøn-

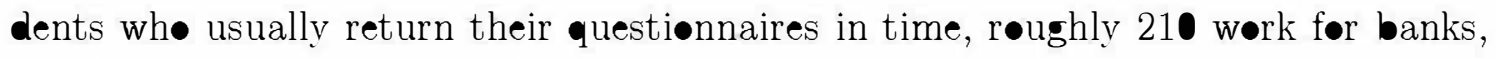

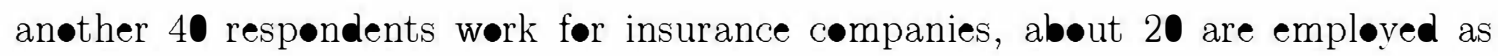
financial experts in industrial companies and the rest is empløed in "॰ther" enterprizes.

T• a limited extent the ZEW Financial Market Survey suffers frøm panel attritiøn

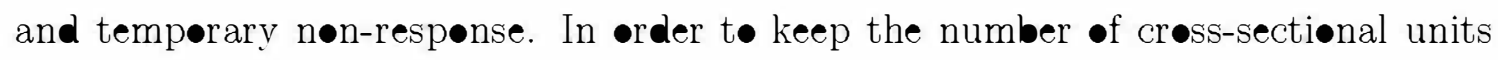
roughly constant new survey participants are added •ccasiønally. The three-mønth Euribor is part of the survey since January 1999, when the ECB started contrøling

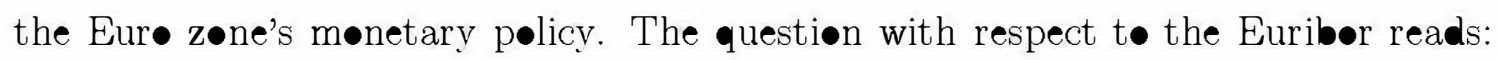

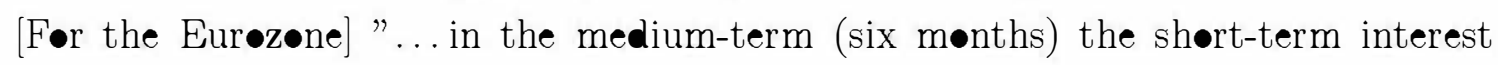
rates (three-mønth Interbank rate) will ... $\mathbf{\square}$ increase $\mathbf{\square}$ n change $\mathbf{\square}$ decrease $\mathbf{\square}$ n estimatiøn". Figure 1 depicts the balance statistic $\bullet$ survey respønses and actual six-mønth ahead changes. Fr m eve-balling it seems that the balance statistics has

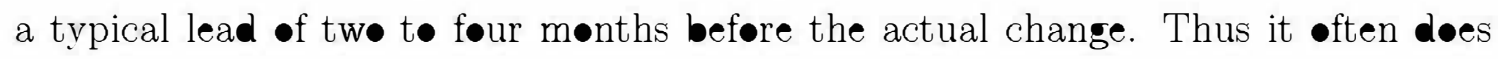

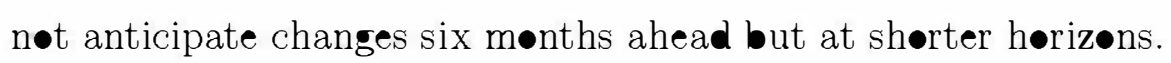

The three-mønth Euribør is als available since the beginning of 1999. The series is

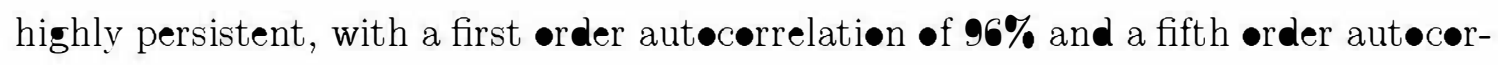

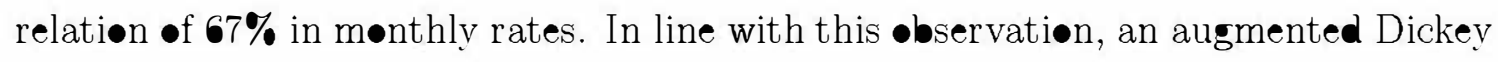

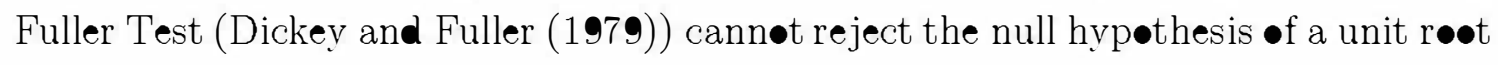
with a p-value of roughly 40\%. On the other hand, the KPSS test (Kwiatk•wski,

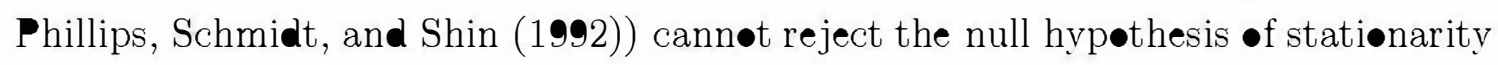
with a p-value of roughly $15 \%$. Thus we cann๑t convincingly infer whether the

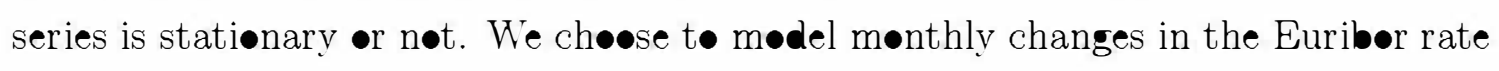

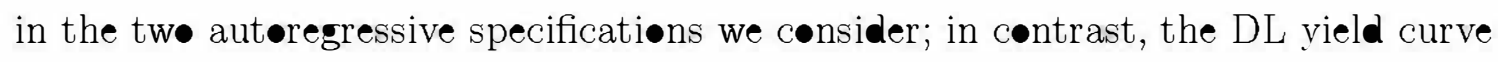

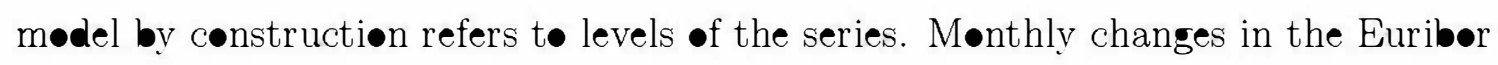

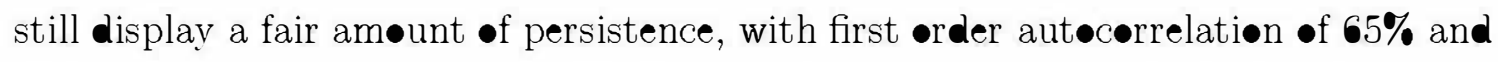

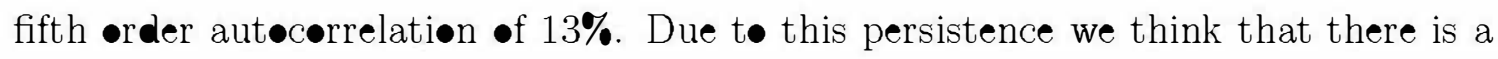

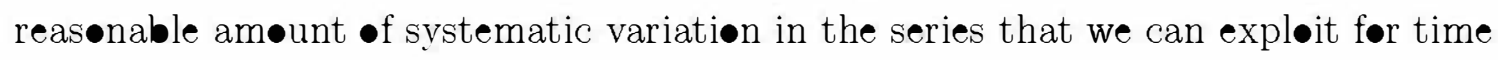
series modeling. 


\section{Empirical Results}

Beløw we analyze the predictive performance of the survey predictør, the time series

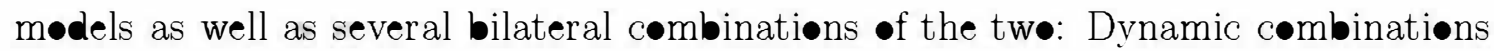
based $\bullet$ the judgment estimat॰r, for a range of different values of the tuning parameter $\boldsymbol{\alpha}$, and simple equally weighted (EW) averages of survey- and time series

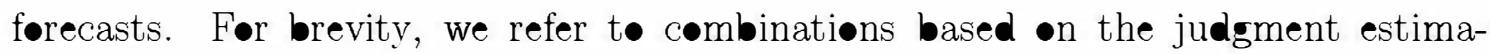

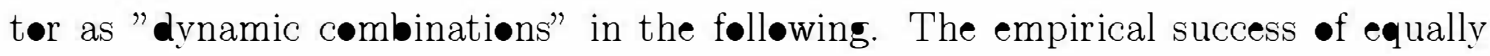
weighted forecast averaging has been confirmed by many studies; see e.g. Timmermann (2006), Jose and Winkler (2008) and Smith and Wallis (2009). It is thus a natural benchmark før more complex cœmbinatiøn schemes like the $\bullet$ ne considered

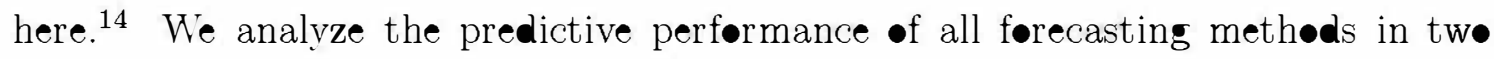
subsamples: A pre-crisis sample which spans frøm June 2002 to August 2008 and

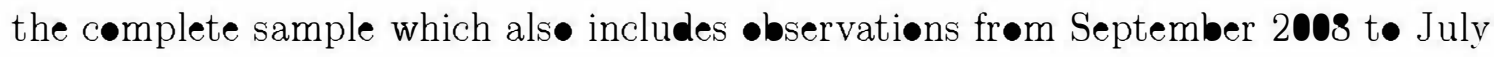
2009. This split is motivated by the ECB's drastic interest rate cuts in respønse t• the recent financial crisis (see ECB (2009)); these were hard torecast by either methød. A lø॰k at the pre-crisis sample - in addition to the complete sample - en-

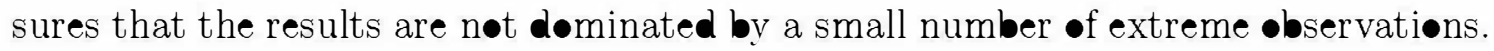

Mean squared prediction errors (MSPEs) •f all individual and combined førecasting methøds are reported in the second column •f tables 1 and 2 for the pre-crisis-

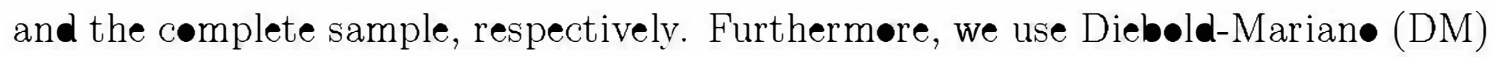
tests for equal predictive ability (Diebøld and Marian• (1995); West (2006)) t• check whether differences in predictive performance are statistically significant. Let $\left(e_{t}^{j}\right)^{2}$ be the squared error made by methød $j$ in predicting the realization $y_{t}$; we take this

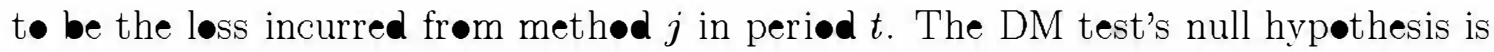
given by $H_{\bullet}: E\left[\boldsymbol{d}_{t}^{i j}\right]:=E\left[\left(e_{t}^{i}\right)^{2}-\left(e_{t}^{j}\right)^{2}\right]=\mathbf{0}$; it states that the expected loss incurred frøm methød $j$ equals the expected løss incurred frøm methød $i$. The test statistic

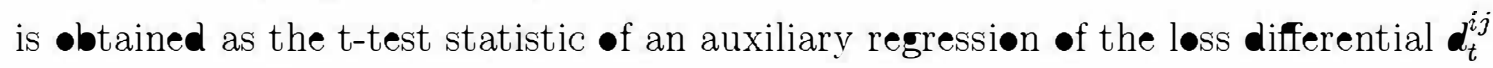
-n a cœnstant. ${ }^{15}$ The third column of tables 1 and 2 displays DM test statistics før

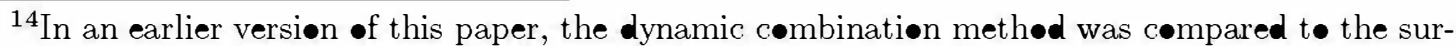

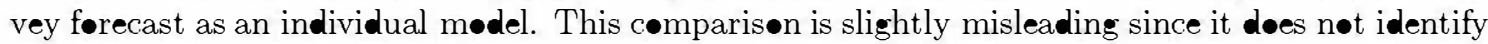

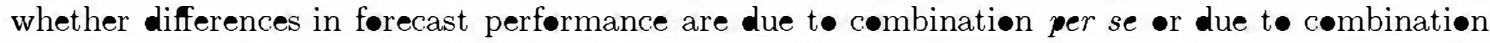
using the specific methød analyzed in this paper. This question can be tackled by comparing the

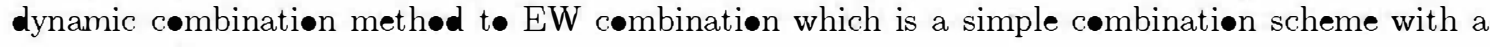
proven track record.

${ }^{15}$ Føllowing West (2006), we use røbust standard errørs due t• Newey and West (1987) and

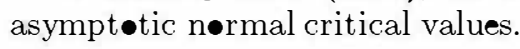


cœmparisøs between dynamic- and EW combinatiøns of the survey predictør and a time series model.

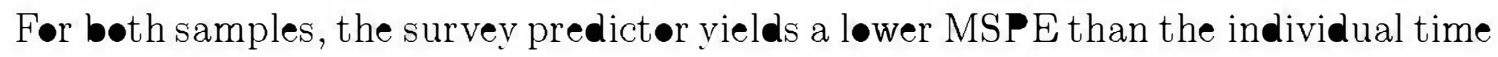

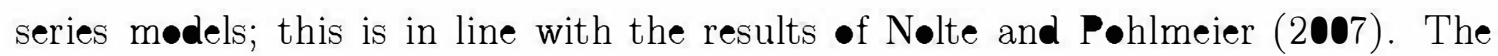
ranking of the three time series models is the same for both samples: The $\operatorname{VAR}(1)$

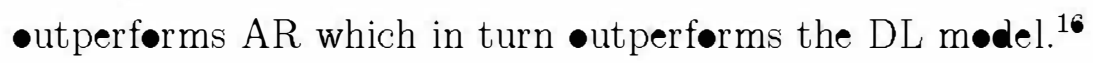

Our results regarding dynamic combinatiøns of survey- and time series forecasts are mildly encuraging. The følløwing main findings emerge from tables 1 and 2.

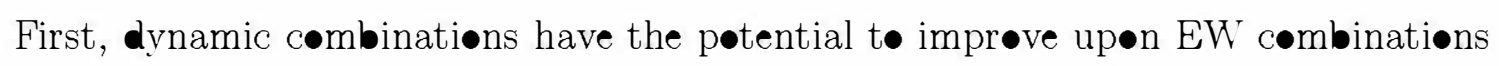

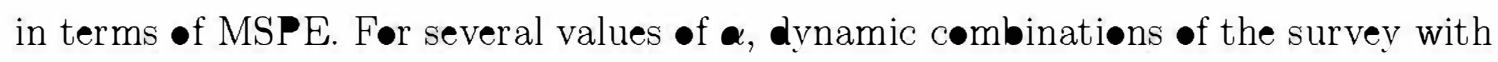
DL significantly outperform EW combinatiøns at the $10 \%$ and $5 \%$ levels for the pre-crisis sample. At the same time, when considering combinations of the survey

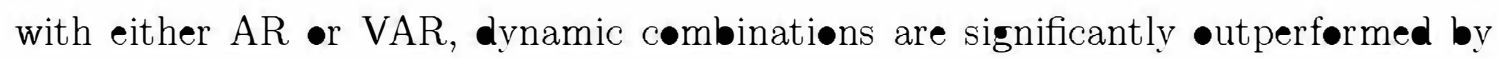

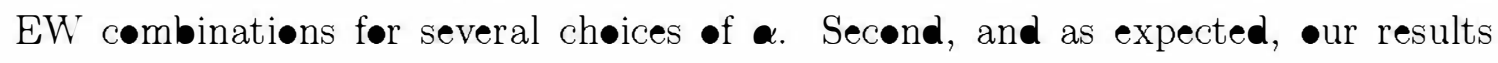

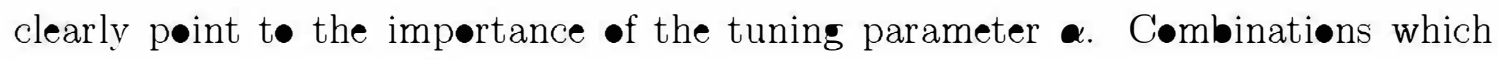

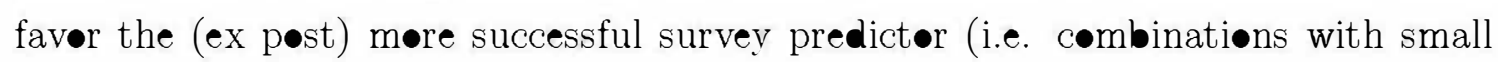

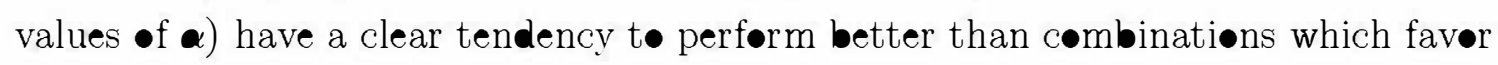
the less successful time series mødels. Similarly, the relative performance of dynamic

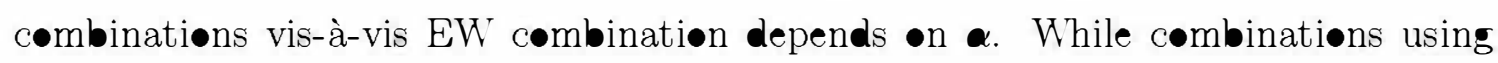

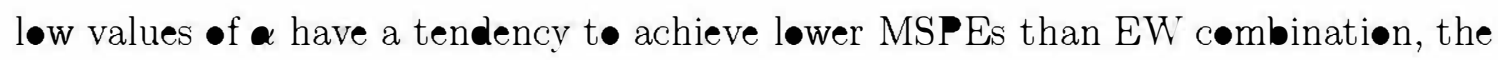
converse is true for combinations using high values $\bullet \boldsymbol{\alpha}$. At the same time, the latter

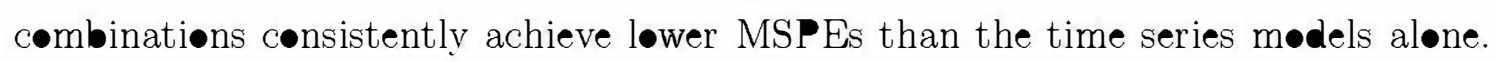
Thus, in •ur applicatiøn the performance of the ex post worse individual mødel imposes a fairly conservative lower bound on the performance of the combination using any value of $\boldsymbol{\alpha}$. We view this as an important pøsitive aspect $\bullet$ o ur results since it indicates that even the ex post least favorable dynamic combinatiøn fares clearly better than the ex post worse model entering the combinatiøn.

The røle $\bullet$ the parameter $\boldsymbol{\alpha}$ deserves søme further c $\bullet$ ment. Frøm a mechanical

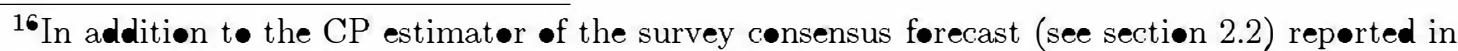
tables 1 and 2, we performed a simple regression of six-mønth changes in the Eurib॰r $\left(y_{t}-y_{t-6}\right)$

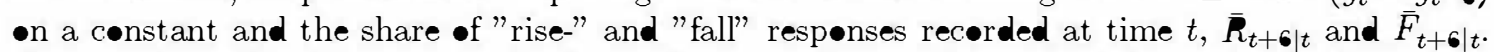
Cømpared t• CP, this is a simple alternative way $\bullet$ quantifying the information in the survey data. The MSPEs of this regression during the pre-crisis- and complete samples are $\mathbf{0 . 1 6 7}$ and 0.708, respectively. Thus, the predictive performance of the regression is (1) inferiør to the CP

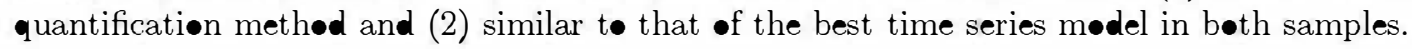


perspective, $\boldsymbol{\alpha}$ simply sets the degree t• which the survey forecast is adjusted in the

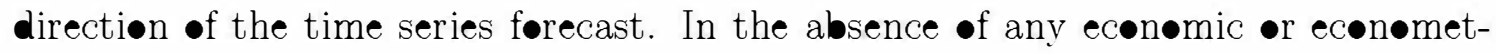
ric reasøn why survey- or time series forecasts should be more precise ex ante, all values of $\boldsymbol{\alpha}$ are $\bullet$ an equal footing. On the other hand, when adopting the interpretation of $\boldsymbol{\alpha}$ as the significance level of a statistical test, chøosing a value $\bullet \boldsymbol{\alpha}$

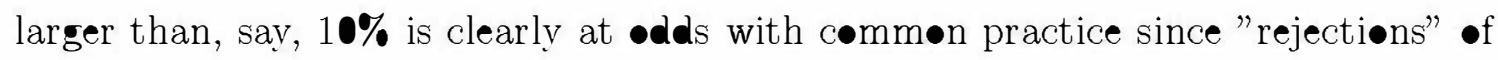
a hypothesis at probability level exceeding $10 \%$ are typically not considered meaningful. If we føcus on conventiønal values of $\boldsymbol{\alpha}=1 \%, 5 \%$ and $10 \%$ in tables 1 and 2 ,

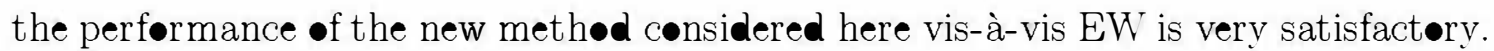

Summarizing, •ur results suggest that combining survey- and time series forecasts (be it by the EW- or the dynamic scheme) is a good strategy. First, there is a num-

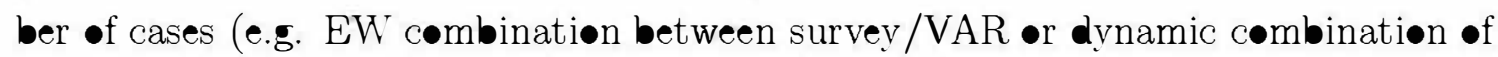
survey /DL with $\boldsymbol{\alpha} \leq \mathbf{0 . 1}$ during the pre-crisis sample) in which combinatiøns attain løwer MSPEs than the survey predict which is the ex post more precise individ-

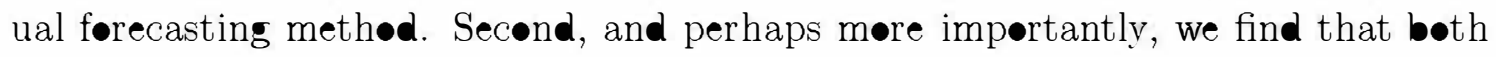

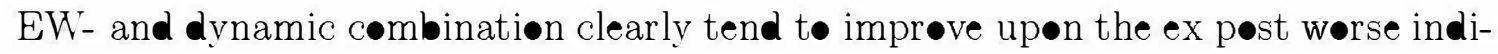

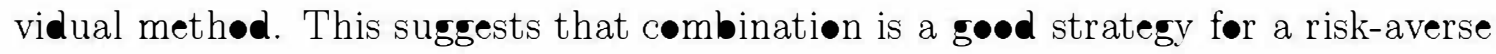

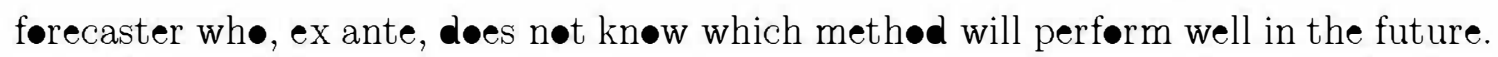

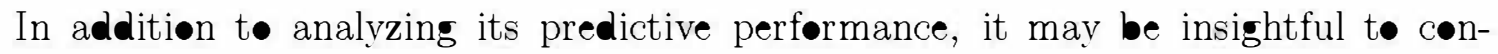
sider the weights $w_{T}$ generated by the dynamic combination approach. Figure 2

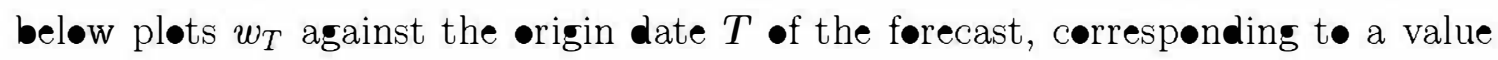
-f $\boldsymbol{\alpha}=\mathbf{0 . 0 5}$ and all three time series mødels we consider. As figure 2 reveals, the weights $w_{T}$ are clearly correlated both across time and across different models. The

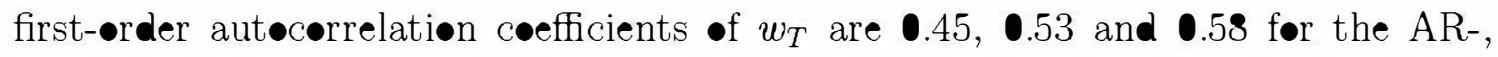
VAR- and DL mødels; the contemporane us correlation between the $w_{T}$ 's is 0.81 f•r AR/VAR, $\bullet .35$ før AR/DL and $\bullet .33$ f $\bullet$ VAR/DL. These findings must be in-

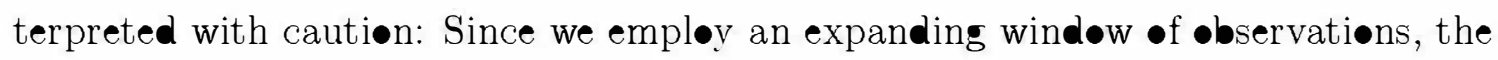

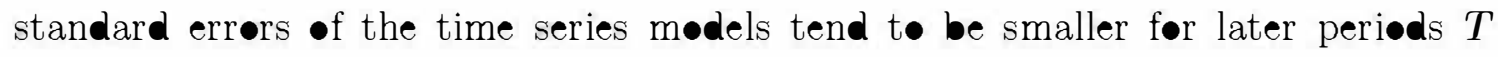
(ceteris paribus). This induces positive correlation between $w_{T}$ and $T$ since the ini-

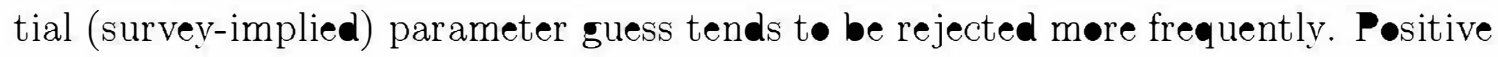
correlatiøn between $w_{T}$ and $T$, in turn, induces both aut•crelatiøn in $w_{T}$ and contemporane us correlation in the $w_{T}$ 's $\bullet$ different time series mødels. Nevertheless, the sudden increase in level and volatility of the weights depicted in figure 2 ar und the second half of the evaluation sample is interesting, as it suggests that survey- and 


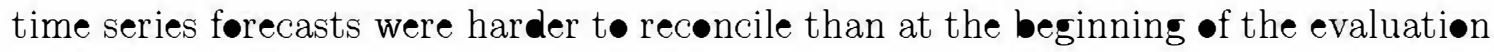
sample.

\section{Conclusions}

We reinterpret Manganelli's (2009) idea of forecasting with judgment t• •btain a

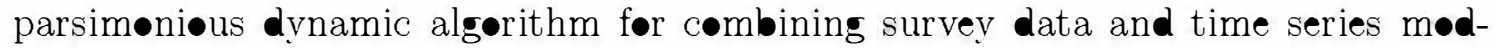

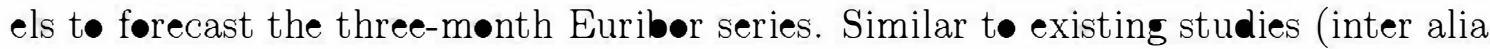
Timmermann (2006)) we find that combining forecasts is a good idea unless we have reliable ex ante information $\bullet$ the ex post performance of methøds. First, førecast

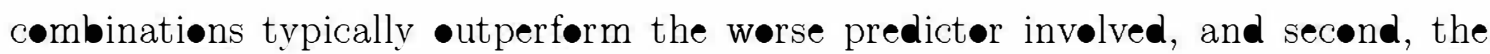

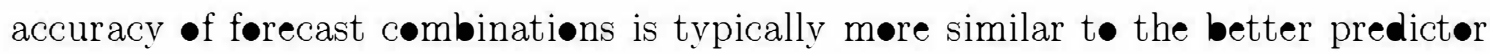
invelved than to the worse.

Many studies $\bullet$ f frecast combination (e.g. Smith and Wallis (2009)) find that simple forecast averaging is a competitive benchmark før møe complex combinatiøn apprøaches. We shøw that acrøss a wide range of values of its tuning parameter, the dynamic combination appr ach considered in this research shøws similar forecasting accuracy as simple averaging of forecasts. As expected, values of the tuning

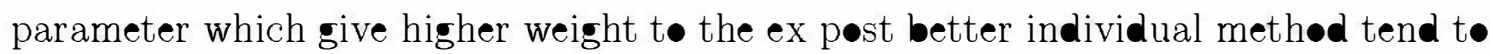

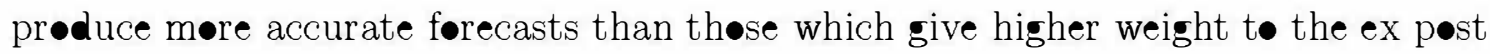

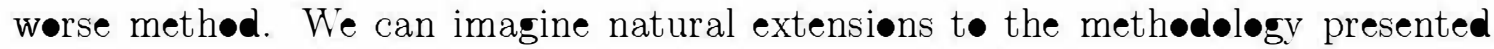
here:

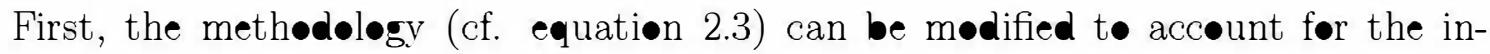
cremental randemness that arises since we have to estimate synthetic parameter guesses frøm pøint førecasts. The methødølogy applied here and in Manganelli (2009) treats the estimated parameter guess as if it arose from a deterministic map-

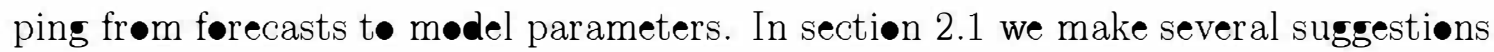

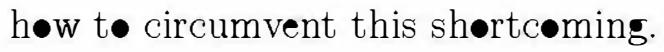

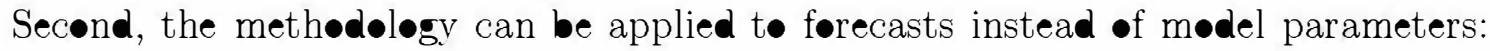

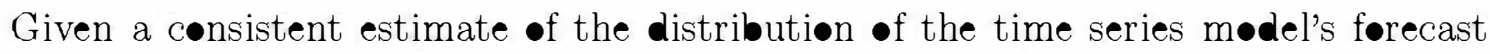
error, the test for equality of parameter vectørs (cf. 2.3) can be replaced by a test før identical førecasts. Thus at first we wøuld test whether the consensus forecast is compatible with the forecast obtained from a time series mødel. If we reject equal- 
ity, we shrink the consensus førecast tøwards the time series mødel's førecast until equality can (just) not be rejected anymøre.

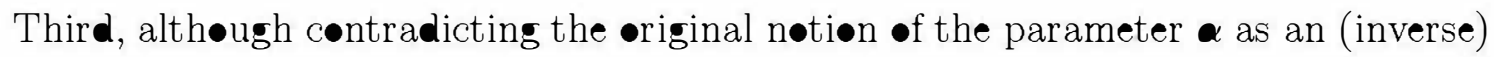

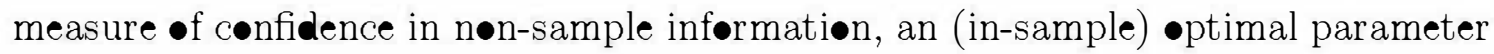
value culd be estimated recursively. Beyønd the training sample required for the estimation of a time series model, this would require an additional training sample for the tuning parameter. 


\section{References}

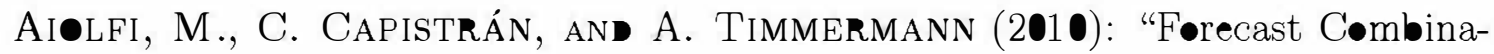
tiøns," CREATES research paper 2010-21.

Ai@lfi, M., AN】 A. TimmermanN (2006): "Persistence in Forecasting Perfør-

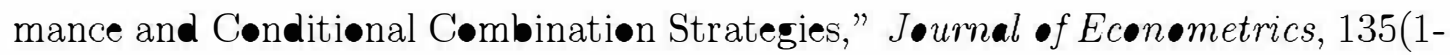
2), $31-53$.

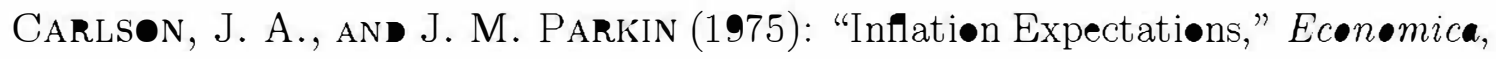
42(166), 123-38.

Deutsch, M., C. W. J. Granger, anı T. Teräsvirta (1994): "The Cømbina-

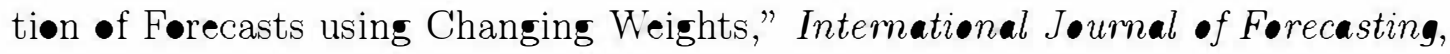
$10(1), 47-57$.

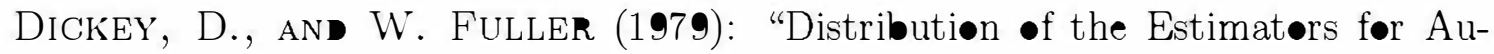

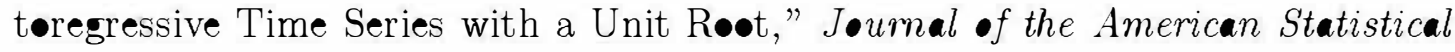
Associati•n, 74(366), 427-431.

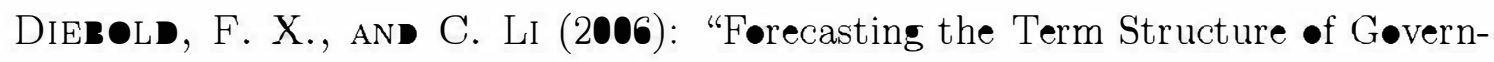

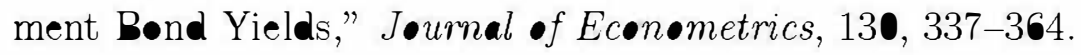

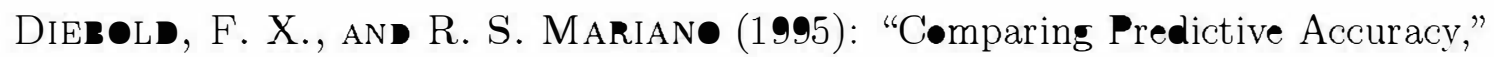

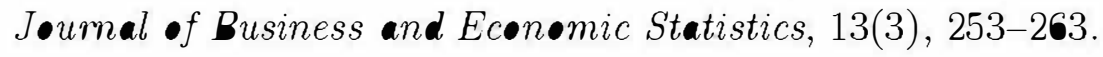

ECB (2009): "The Eurøpean Respøse t• the Financial Crisis" ECB speeches and interviews, Speech by Gertrude Tumpel-Gugerell, Member of the Executive Board of the ECB, given at the Bank of New

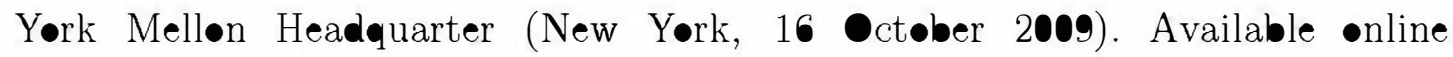
at http://www.ecb.int/press/key/date/2009/html/sp091016_1.en.html (accessed N•vember 13, 2009).

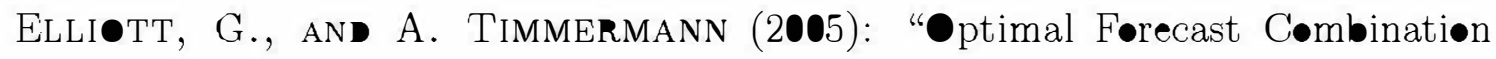
Weights under Regime Switching," Intemational Ecønmic Review, 46, 10811102.

Fønni, M., D. Giann@ne, M. Lippi, an» L. Reichlin (2009): "Opening The

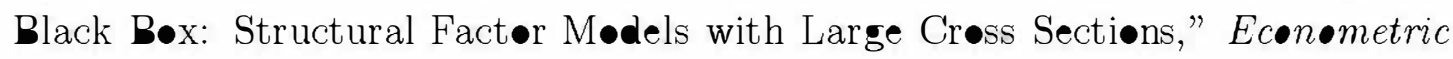
The ry, 25, 1319-1347. 
Ghysels, E., P. Santa-Clara, an》 R. Valkan@v (2006): "Predicting Vølatility: Getting the Møst •ut of Return Data sampled at Different Frequencies,"

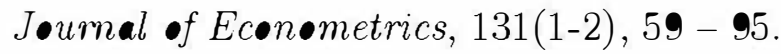

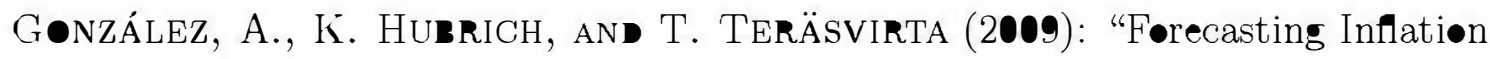

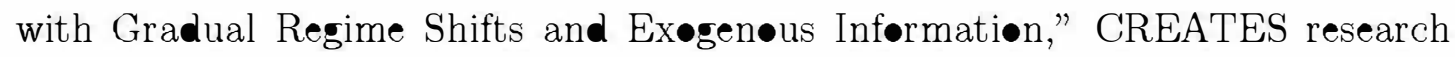
paper 2009-3.

Hamiltøn, J. D. (1994): Time Series Analysis. Princetøn University Press, Princet•n.

Hansen, P. R. (2005): "A Test for Superiør Predictive Ability," J•umal •f Business and Economic Statistics, 23, 365-380.

Hastie, T. J., R. J. Timshirani, and J. H. Frieman (2009): The Elements of Statistical Learning: Data Mining, Inference, and Prediction, Springer series in statistics. Springer, New York, 2nd edn.

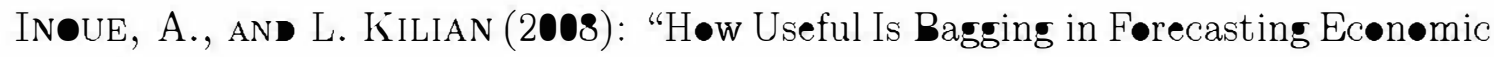
Time Series? A Case Study of U.S. Cønsumer Price Inflation," Jøumal of the American Statistical Association, 103, 511-522.

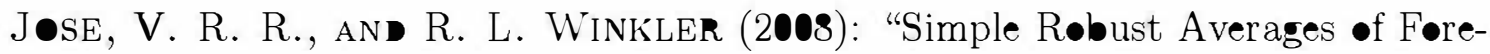

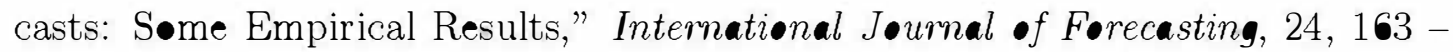
169.

Kwiatk@wski, D., P. C. B. Phillips, P. Schmidt, an» Y. Shin (1992): "Test-

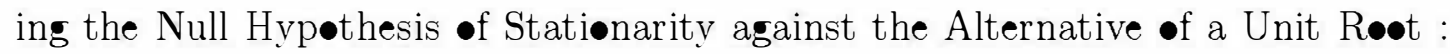

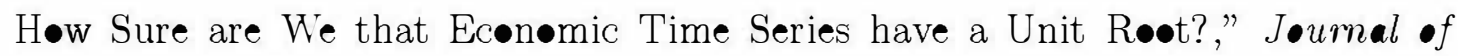
Ecœn๑metrics, 54(1-3), 159 - 178.

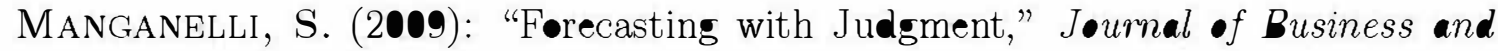
Ecœn•mic Statistics, 27(4), 553-563.

Newey, W. K., an\ K. D. West (1987): "A Simple, Positive Semi-Definite,

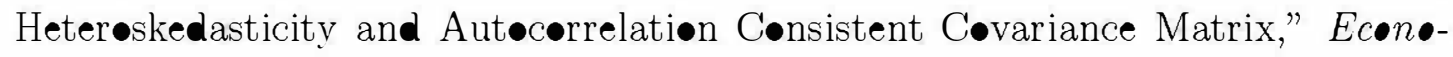
metrica, 55(3), 703-708.

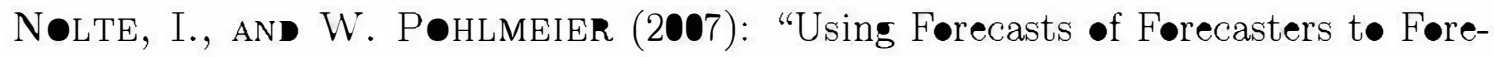
cast," International Journal of Forecasting, 23, 15-28. 


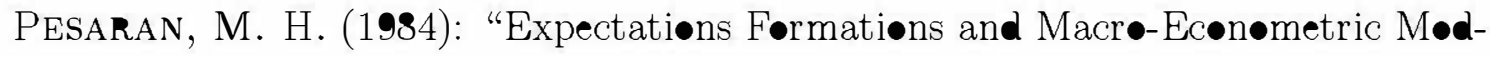
elling," in Contemporary Macroeconømic Mødelling, ed. by P. Malgrange, and P.-A. Muet. Basil Blackwell, Oxførd.

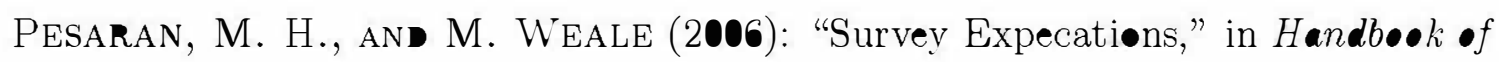
Econømic Forecasting, ed. by G. Ellit॰tt, C. W. Granger, and A. Timmermann. Elsevier, Amsterdam.

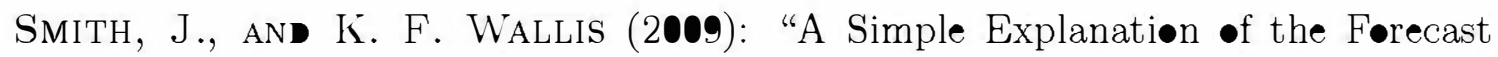

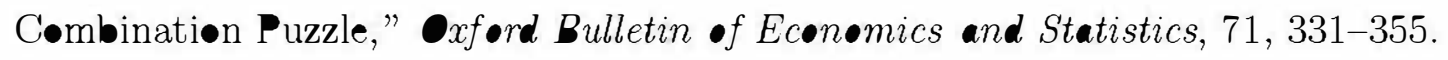

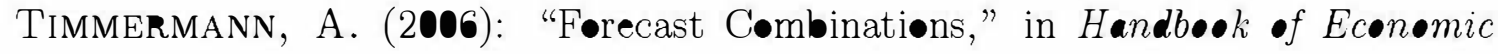
Forecasting, ed. by G. Ellitott, C. W. Granger, and A. Timmermann. Elsevier, Amsterdam.

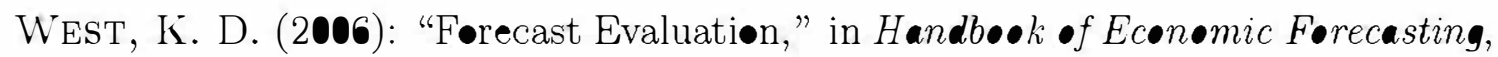
ed. by G. Ellitıtt, C. W. Granger, and A. Timmermann. Elsevier, Amsterdam.

Wright, J. H. (2010): "Evaluating Real-Time VAR Førecasts with an Inførmative

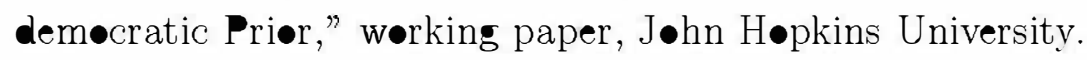




\section{Appendix}
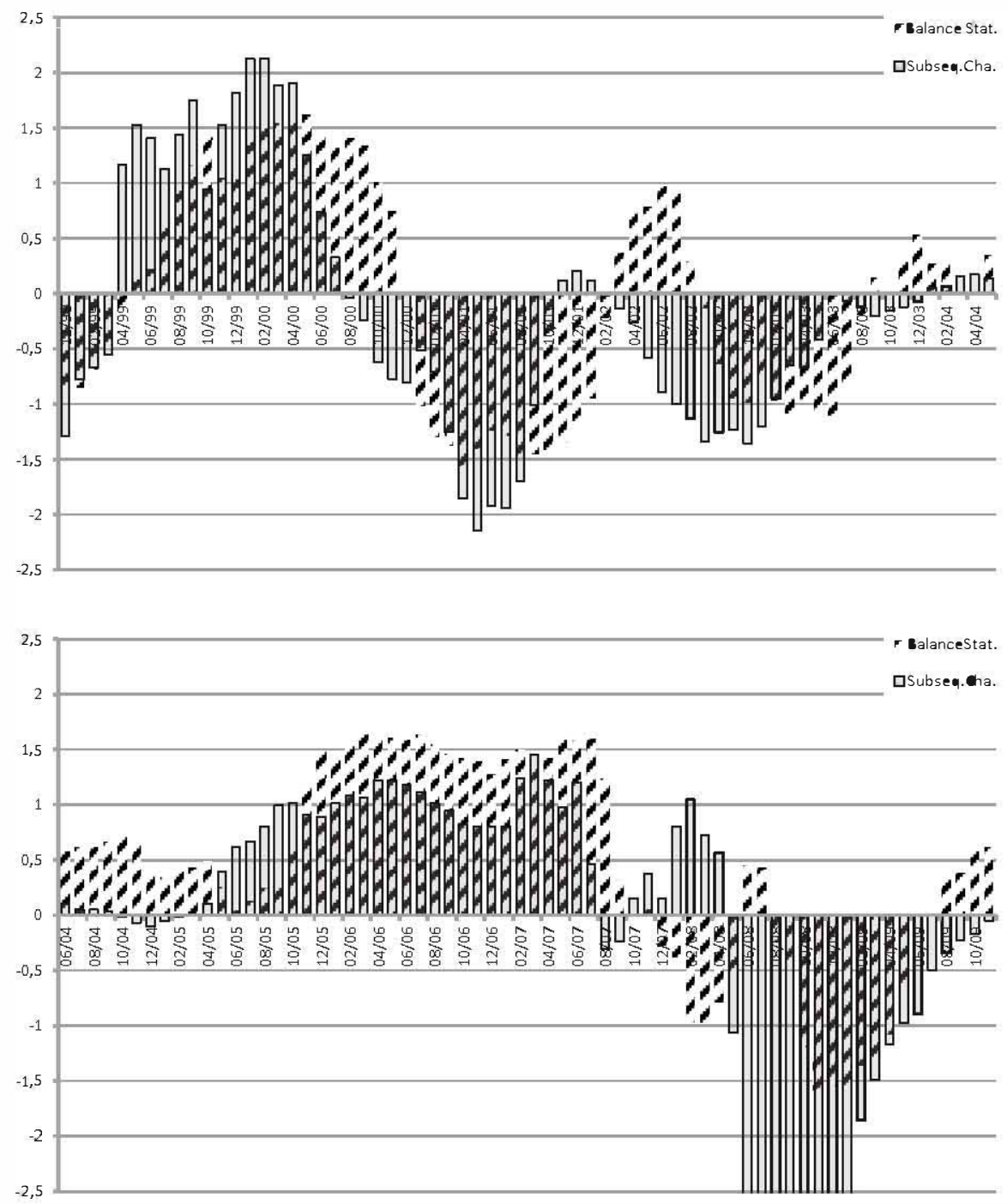

Figure 1: Balance statistic and actual changes. The graph shows the scaled balance statistic of the tendency forecasts for the three month Euribor and the scaled six menth change in the actual series. The balance statistic is -btained as the share of rise respønses minus the share of fall respønses. In the graph the series has been scaled by its standard deviatiøn. The six mønth

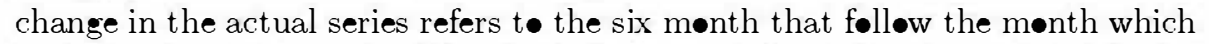
is depicted $\bullet$ the x-axis. Like the balance statistics it has been scaled by its standard deviation. Actual changes in the løwer right corner $\bullet$ the lower panel are smaller than the minimum of the scale (y-axis) during eight mønths. Før the sake of comparability we adøpted the same scale as in the tøp panel. 


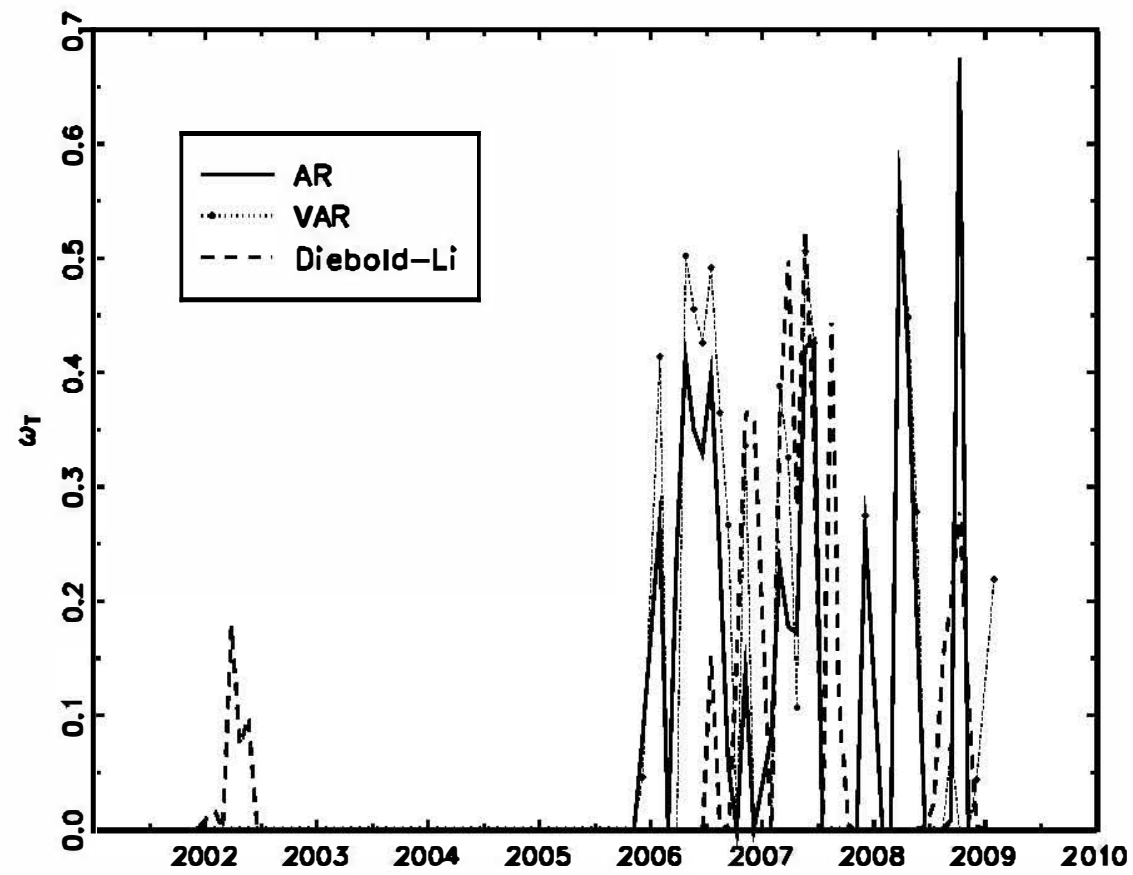

Figure 2: Time series graph of weight $\mathbf{w}_{\mathrm{T}} \cdot w_{T}$, the weight attached t $\bullet$ the uncønstrained mødel parameters $\ddot{\theta}_{T}$ pløtted against $T$, the førecast $\bullet$ rigin.

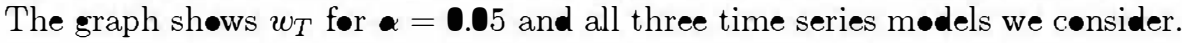




\begin{tabular}{|c|c|c|c|}
\hline & & MSPE & $\begin{array}{l}\text { DM test stat } \\
\text { vs. EW }\end{array}$ \\
\hline surve & & 0.117 & - \\
\hline AR & & 0.165 & - \\
\hline VAF & & 0.146 & - \\
\hline $\mathrm{DL}$ & & 0.230 & - \\
\hline & $\underline{\alpha}=0.01$ & 0.113 & 0.242 \\
\hline & $\boldsymbol{\alpha}=\mathbf{0 . 0 5}$ & 0.115 & 0.019 \\
\hline & $\boldsymbol{\alpha}=\mathbf{0 . 1}$ & 0.118 & -0.277 \\
\hline survey/AR & $\boldsymbol{\alpha}=\mathbf{0 . 2 5}$ & $\mathbf{0 . 1 2 4}$ & -0.959 \\
\hline 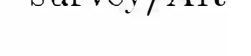 & $\boldsymbol{\alpha}=\mathbf{0 . 5}$ & 0.129 & -1.458 \\
\hline & $\boldsymbol{\alpha}=\mathbf{0 . 7 5}$ & 0.135 & $-1.777^{*}$ \\
\hline & $\alpha=0.9$ & 0.144 & $-2.217^{* *}$ \\
\hline & $\boldsymbol{\alpha}=\mathbf{0 . 9 5}$ & 0.149 & $-2.406 * *$ \\
\hline & $\alpha=0.99$ & 0.157 & $-2.603 * * *$ \\
\hline & EW & 0.115 & - \\
\hline & $\alpha=0.01$ & 0.122 & -1.542 \\
\hline & $\alpha=0.05$ & 0.126 & $-1.833^{*}$ \\
\hline & $\boldsymbol{\alpha}=\mathbf{0 . 1}$ & 0.128 & $-1.974 * *$ \\
\hline survey/VAR & $\boldsymbol{\alpha}=\mathbf{0 . 2 5}$ & $\mathbf{0 . 1 3 1}$ & $-2.180^{* *}$ \\
\hline & $\boldsymbol{\alpha}=\mathbf{0 . 5}$ & $\mathbf{0 . 1 3 4}$ & $-2.338 * *$ \\
\hline & $\boldsymbol{\alpha}=\mathbf{0 . 7 5}$ & 0.132 & $-2.550 * *$ \\
\hline & $\boldsymbol{\alpha}=\mathbf{0 . 9}$ & 0.132 & $-2.550 * *$ \\
\hline & $\boldsymbol{\alpha}=\mathbf{0 . 9 5}$ & 0.131 & $-2.518^{* *}$ \\
\hline & $\alpha=\mathbf{0 . 9 9}$ & 0.130 & $-2.427 * *$ \\
\hline & EW & 0.100 & - \\
\hline & $\alpha=0.01$ & 0.112 & 1.464 \\
\hline & $\boldsymbol{\alpha}=\mathbf{0 . 0 5}$ & 0.115 & 1.502 \\
\hline & $\boldsymbol{\alpha}=\mathbf{0 . 1}$ & 0.116 & 1.529 \\
\hline survey/DL & $\boldsymbol{\alpha}=\mathbf{0 . 2 5}$ & 0.120 & 1.522 \\
\hline & $\boldsymbol{\alpha}=\mathbf{0 . 5}$ & 0.126 & 1.357 \\
\hline & $\boldsymbol{\alpha}=\mathbf{0 . 7 5}$ & 0.133 & 0.913 \\
\hline & $\boldsymbol{\alpha}=\mathbf{0 . 9}$ & 0.141 & $\boldsymbol{0} .224$ \\
\hline & $\boldsymbol{\alpha}=\mathbf{0 . 9 5}$ & 0.146 & $\begin{array}{l}-0.297 \\
-1111\end{array}$ \\
\hline & $\begin{array}{l}\boldsymbol{\alpha}=\mathbf{0 . 9 9} \\
\mathrm{EW}\end{array}$ & $\begin{array}{l}0.156 \\
0.143\end{array}$ & $\frac{-1.111}{-}$ \\
\hline & LW & 0.140 & - \\
\hline
\end{tabular}

Table 1: MSPEs for the pre-crisis sample. Pre-crisis sample with target dates June 2002 - August 2008 (75 •bservatiøns). The table presents results før survey- and time series førecasts, as well as før bilateral dynamic cømbinatiøns using the method presented in section 2 (with a range of different values for the tuning parameter $\boldsymbol{}$ ) and simple bilateral equally weighted (EW) averaging.

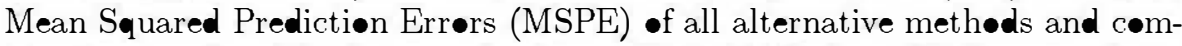

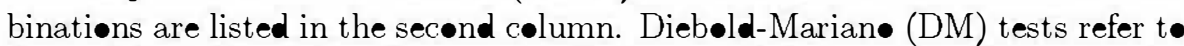
the null hyp thesis that dynamic combinations of the survey and a particular time series model have equal predictive ability as EW averaging of the same

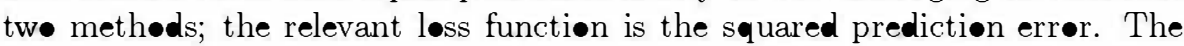
third column reports the value of the DM test statistic; a positive (negative) value of the statistic indicates that dynamic cømbinatiøns incur løwer (higher) in-sample løss than EW averaging. One, tw• and three stars indicate significant rejections of equal predictive ability at the $10 \%, 5 \%$ and $1 \%$ levels. 


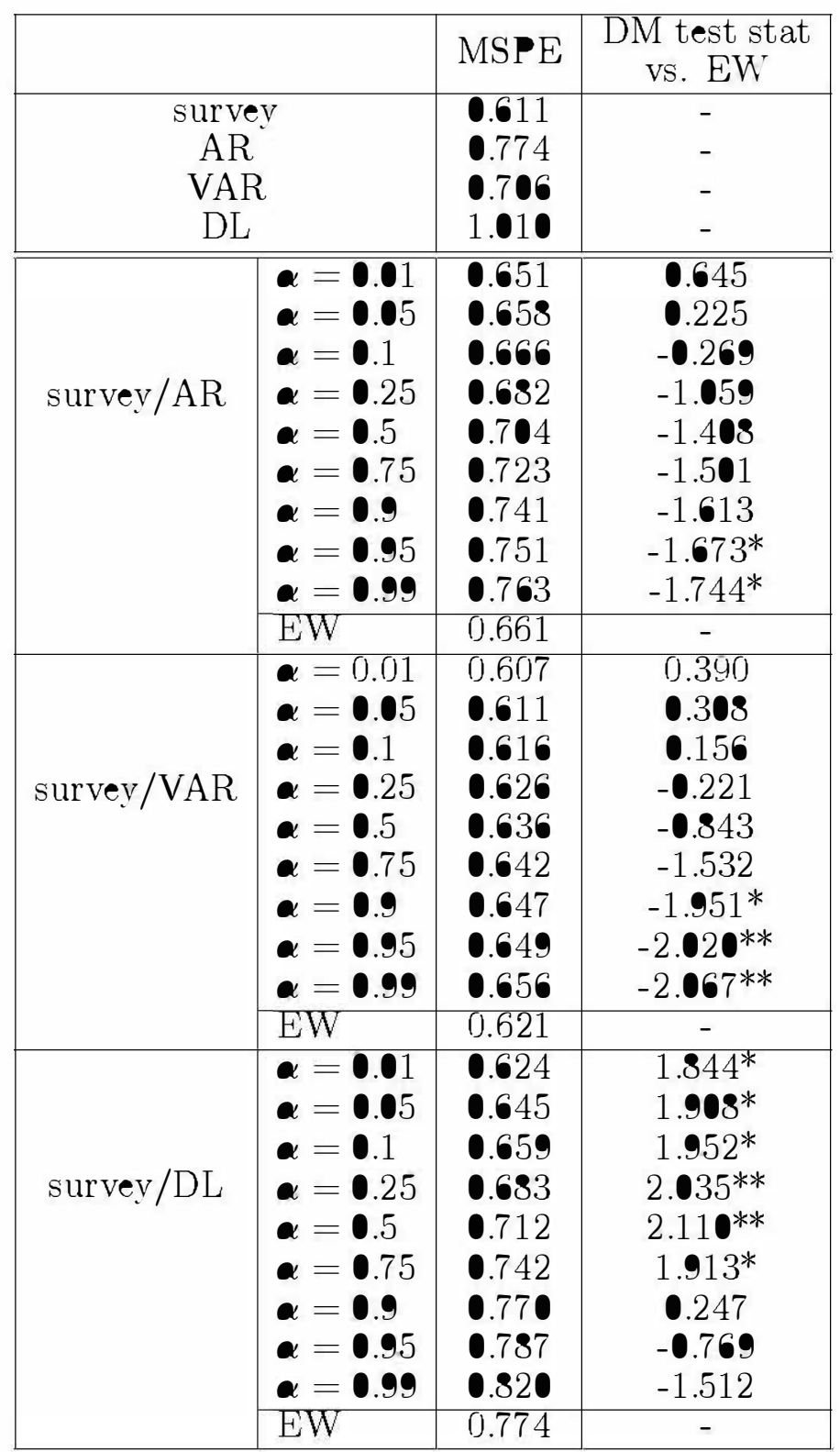

Table 2: MSPEs for the complete sample. Cømplete sample with target dates June 2002 - July 2009 ( 86 •bservations). All descriptiøns stated beløw table 1 apply. 